\title{
La política económica: debates y objetivos
}

\author{
Julio Tascón Fernández
}

\section{INTRODUCCIÓN}

Es algo sabido que la función de los políticos que gobiernan debería consistir en administrar lo público. Dicho de otro modo, la misión de los gobernantes de un país consiste en la administración del sector público de la nación gobernada ${ }^{1}$. La hoja de ruta del partido que gobierna se comprueba en la estrategia desvelada por las políticas económicas que adopta². Otras políticas ciertamente son tanto más transcendentes para el sector público como las denominadas económicas, pero aquí me centraré en estas últimas y su evolución histórica durante el perío-

1 Definición de Sector Público: conjunto de todos los entes públicos que realizan actividades económicas según criterios guiados fundamentalmente por el principio de autoridad. Está compuesto por las Administraciones Públicas (Gobierno central o Estado, Gobiernos Locales y Organismos de la Seguridad Social), por las empresas públicas y por las instituciones financieras públicas. Es un agente económico diferente del sector privado. Véase Martínez Cortiña, Rafael (dir.), Economía Planeta. Diccionario Enciclopédico, Barcelona, Editorial Planeta, 1980, p. 254. Por supuesto se puede acudir al New Palgrave Dictionary para buscar la voz correspondiente en inglés.

2 Una definición que respalda esta idea es la que nos ofrece Luis GÁmir (2008, p. 11): «Se suele argumentar que el núcleo de la Política Económica, como disciplina académica, es el estudio de la relación entre instrumentos y objetivos». Al tiempo añade que habrá pocos autores que estén de acuerdo sobre «cuáles son los instrumentos y cómo clasificarlos, y mucho menos sobre la prioridad de los objetivos». Aclara Gámir (2008, p.12) que ellos, en un principio, habían optado por el triple enfoque de políticas instrumentales, regionales y sectoriales y por objetivos. Pero que más tarde decidieron implicar una cuarta categoría diferenciada para la política autonómica y regional. Además de finalmente añadir una quinta categoría incluyendo la política de integración europea (políticas de ámbito territorial distinto del nacional). Ver también el esquema de CuADRADo Roura (2000, 325), o bien para un esquema claro y pormenorizado respecto a la política monetaria véase por ejemplo: José A. Martínez (2008, 355). 
do que abarca la Transición democrática en España y llega casi hasta la última crisis económica ${ }^{3}$. El sesgo de las diferentes políticas económicas practicadas por los gobiernos conservadores o socialistas permitirá comprender mejor los resultados obtenidos ${ }^{4}$, resultados que deben ayudar a interpretar o a explicar qué grupo político en el Gobierno desarrolló la administración del sector público más eficiente. Dicho con otras palabras, qué partido político consiguió elevar el bienestar económico de los españoles al menor coste posible, al tiempo que mantenía un estándar de coherencia en sus políticas económicas homologable con el desarrollado previamente por sus émulos en el poder. Parece innegable, en todo caso, que la relación entre políticas y resultados contribuya significativamente al debate. Dentro de este artículo extractaré las aportaciones de prestigiosos investigadores sobre las principales políticas económicas desarrolladas durante los treinta años del período de estudio ${ }^{5}$. Destaca el artículo de Enrique

3 La cronología de este artículo abarca el período 1976-2006, e incluso también en ocasiones se alarga hasta el año 2007. Ésta es una crisis global, cuyo comienzo tiene sus orígenes en el sector financiero norteamericano. Se fecha en noviembre de 2007, pero llega hasta nuestros días (noviembre de 2010) y parece innegable que es una gran crisis económica a nivel mundial. Los más avezados apostillan aquello de «se veía venir», por ello tal vez podemos convenir que para la economía la historia es el destino, como así lo afirma MokrR $(1990,3)$. Después de un muy gráfico y geográfico ejemplo con relación a la esperanza de vida al nacer y la renta nacional per cápita concluye: «In economics, history is destiny». También debo apuntar aquí que cualquier Política Económica forma parte de lo que D. S. Watson calificaba como política pública, que no es sino un variado conjunto de políticas (social, económica, exterior, de defensa,...) desarrolladas por los gobiernos e interrelacionadas entre sí. Ver CuAdrado Roura (2001, 20).

4 Las diferentes políticas económicas adoptadas por cada Gobierno muestran, con su correspondiente reflejo en las cifras de las diferentes partidas de los presupuestos generales del Estado, el cariz de la orientación dada por esa administración de lo público.

$5 \mathrm{Al}$ recapitular sobre las políticas económicas de los diferentes gobiernos espero llegar a entender mejor las enseñanzas contenidas a través de los debates y objetivos de las políticas económicas. Según afirma Skidelsky la política económica es «un método organizado de pensar sobre algunas situaciones reales y sobre el diseño de las instituciones capaces de conservar el bienestar más allá de las acciones de un gobierno en un lugar y tiempo concreto», cita en MuÑoz Cidad $(2008,62)$. Debo destacar como más relevantes y significativas las contenidas en el volumen colectivo dirigido por Luis Gámir (dir.); Javier Casares y Carlos Velasco (coords.) (2008), así como otras del mismo autor, ej. Luis GÁmir, Pedro Durá (2004) contenidas en el monográfico publicado por la Revista del Institu to de Estudios Económicos, sobre El progreso de la economía española en los últimos 25 años, y también de manera muy significativa la contribución de Tomás Mancha NAvarRo (2008) incluida en el volumen colectivo ya referido. Por otra parte están también las lecturas publicadas en la denominada Serie Marrón del Círculo de Empresarios elaboradas con una orientación algo diferente a lo más académico ya mencionado. Por ejemplo el número dedicado a la Política económica española: ¿qué hemos aprendido tras diez años de integración? (diciembre, 1995); o el dedicado a las alternativas para el crecimiento de España consideradas con relación a su pertenencia a la Unión Europea; o bien el dedicado 
Fuentes Quintana que analiza la etapa de la Transición hasta 1988. El profesor Fuentes Quintana fue autor y testigo de excepción de las políticas de ajuste a la crisis del petróleo, para la integración en la Comunidad Económica Europea (CEE). Es de sobra conocido que el principio de ese ajuste se encuentra en los Pactos de la Moncloa, así como es notorio que, en gran medida, fueron obra del mismo Fuentes Quintana. Su interés era garantizar la Transición política hacia una democracia pluralista (Fuentes Quintana;1988, 36).

Existen dos planteamientos, que no resultan opuestos sino complementarios, para concluir sobre qué partido político lo hizo mejor -en lo tocante a la política económica- cuando estaba en el Gobierno: 1) observar la percepción básica e intuitiva que tienen los ciudadanos del bienestar económico durante el período $^{6}$; 2) conocer alguna solución académica que aporte una forma de evaluar lo que fue mejor para los españoles durante ese lapso temporal. Entre el primer tipo de planteamiento y el segundo encuentro que la aportación de Mancha Navarro (2008) nos provee, por ahora, de la mejor aproximación al tema. Ésta consiste en comprobar si los partidos gobernantes tuvieron comportamientos electoralistas o partidistas, de modo que se pueda afirmar la existencia de manipulación previa a las elecciones para aumentar sus posibilidades de permanecer en el poder. O bien que se compruebe la existencia de diferencias sistemáticas y permanentes en los resultados económicos de alguno de los tres partidos-UCD, PSOE, PP- que tuvieron responsabilidades de gobierno ${ }^{7}$.

En base a la bibliografía disponible se trata aquí la evolución y el impacto de las políticas económicas aplicadas por los diferentes partidos políticos cuando estuvieron gobernando el país en el período 1976-2006². La finalidad es mostrar

en 2008 a responder a la pregunta ¿Cómo garantizar el futuro?

6 Puede considerarse dicha percepción como estimador de la bondad de la respectiva administración del sector público, por el partido de signo conservador o socialista. Su conocimiento es posible a través de encuestas y entrevistas, sobre las que suelen estar más especializados los sociólogos y los politólogos.

7 El ciclo partidista supone que los gobiernos conservadores persiguen la estabilidad de precios por encima de cualquier otro objetivo macroeconómico. Por ello su política económica debería tener un marcado carácter restrictivo, aunque así lograra menores tasas de crecimiento. Los gobiernos no conservadores (socialistas, socialdemócratas) apuntarían como logro primordial el mayor nivel de empleo, o bien la menor tasa de desempleo, por lo cual su política macroeconómica tendría un carácter expansivo, aún a costa de una elevación de precios. La evolución de estos dos objetivos: inflación y desempleo debería reflejar las orientaciones políticas de los partidos en el gobierno de la nación. Ver MANCHA NAVARRO $(2008$, 91-92 y 104).

8 Queda incluido en ocasiones también el año 2007 como he indicado más arriba, en la nota 5. La bibliografía «ad hoc» ofrece algunas evidencias notables que permiten concluir, a la hora de recapitular, sobre los objetivos y los principales debates de las diferentes políticas económicas desarrolladas estos últimos treinta años. 
el resultado de las principales decisiones del ejecutivo sobre la política económica y sus consecuencias para el referido bienestar económico de los ciudadanos de España. Este objetivo será mi propósito principal durante las siguientes páginas, para terminar con un balance general, para dicho período, acerca de cuál fue el partido político que administró mejor lo público.

Las tendencias que trascienden el detalle de los epígrafes siguientes son más políticas que económicas, como en buena lógica era de esperar. En primer lugar está el común denominador, para los gobiernos conservadores y también para los socialistas, de un objetivo preeminente: consolidar la democracia (identificable sobre todo en el período 1977-1996). En segundo lugar figura el objetivo preponderante de los sucesivos gobiernos, desde el de Felipe González ya en 1986 y al menos desde 1993 hasta el año 2006 inclusive (aún perdura en la agenda política), de ser miembro de pleno derecho y ejercer como tal dentro de la Unión Europea. La evolución de las políticas económicas arbitradas bajo el signo de esos dos principales referentes logra que éstos animen e inspiren el resto de objetivos y estrategias. El debate queda servido en el último apartado dedicado a sugerir y deslindar una quimera: qué partido había maximizado el bienestar económico de los españoles.

Lograr cierta coherencia en el argumento expositivo de esta reflexión académica obliga necesariamente a eludir ciertos aspectos principales de algunas políticas económicas. La reflexión sobre el tema objeto de tratamiento se basa en trabajos y estudios ajenos a una investigación propia. La recapitulación de las políticas económicas consideradas aquí debe mostrar la trayectoria seguida por los diferentes gobiernos conservadores o progresistas, para concluir en el balance que realiza Mancha Navarro (2003). Desconozco otra visión global de ninguna otra autoría que trate la política económica desarrollada durante aquellos treinta años del período 1976-2006, para interrogarse e incidir -al uso norteamericanosobre si fue una buena o una mala cosa. La tesis de Mancha Navarro comprueba, no sin experimentar ciertas dificultades ${ }^{9}$, qué partido en el Gobierno lo hizo mejor, según una valoración del coste político asumido -políticas electoralistas y/o partidistas- para alcanzar el bienestar económico de los españoles.

Me conformo con arreglar una somera descripción de los principales hitos en la política económica del país, según la versión latente al título de este artículo, «tal como lo explico y lo recuerdo», porque la interpretación personal juega

9 Mancha Navarro $(2008,105)$ reconoce las dificultades para ajustar los planteamientos teóricos de la teoría del Political Business Cycle, a la realidad española. Esto lo convierte en un ejercicio riesgoso, pero como ya he indicado no conozco otro que intente algo parecido. 
un papel discriminador bastante decisivo cuando se trata de actividad y política económicas ${ }^{10}$. El punto de vista de los economistas clásicos ingleses, que frecuentemente veían en la economía una ciencia normativa a la que los juicios de valor del economista no eran ajenos, ni tal vez convenía que lo fueran, contenía un concepto de la economía dinámico y pretendía conservar un fuerte contacto con la realidad (Trias Fargas; 1973, 259). Tampoco se libra la historia económica de esos juicios de valor pues quedan atemperados con la racionalidad actual, desde la que se hacen las preguntas al pasado.

Los cambios estructurales incluidos por las diferentes políticas económicas también quedan fuera del objeto a tratar en este artículo. Sin embargo el objetivo que me propongo se diseña bajo la consciencia de que los manuales como el de Cuadrado Roura, Gámir, etc. contienen una correcta sistematización y una excelente exposición de todo tipo de políticas e instrumentos, además de dar explicaciones sobre los referidos cambios, con lo que ofrecen un cuerpo básico de conocimientos y de referencia para las consultas del lector. Mi contribución aquí recorre el camino del análisis según la importancia de los temas para la economía política del país. Resulta bastante obvio que el sesgo adoptado dimana de «cómo explico y cómo recuerdo» esas etapas. El enfoque teórico adoptado se basa en priorizar el análisis desde lo más general y contemplar la actividad económica según su mayor peso relativo, porque así se da importancia a las políticas que implican a la mayor parte de la población española, durante el mayor lapso temporal del período de estudio.

Desde este enfoque he considerado primordial la Democratización del país como aspecto predominante sobre el tratamiento de las políticas económicas y asimismo, después he indicado que le sigue en importancia la Europeización. Estas dos tendencias, entre las principales preocupaciones políticas fueron, a mi parecer, las preponderantes entre las acaecidas dentro del período, tanto por su calado como por su peso específico. Para identificar la persistencia de esas dos tendencias dentro de la agenda política he acudido al criterio del miedo de un partido a quedar desestabilizado, por utilizar patrones electoralistas o partidistas, cuando desempeña las funciones de gobierno de un Estado. Ese tipo de

10 Debo dejar constancia de que tengo memoria de mi propia percepción de esta etapa de la economía política española. Precisamente cuando el que suscribe empezaba su licenciatura en Economía, era coincidente con el mismo año en que moría Franco, en 1975, es decir cuando el proceso de Transición daba sus primeros pasos, o bien según otros ya los había iniciado desde 1973 ..., para otros autores podría haber empezado la Transición ya en 1971 ... Sólo definir una cronología precisa ya resulta problemático, cuanto más dilucidar los matices por los que se elige tratar de un sector de actividad concreto, o bien de las políticas económicas dirigidas a orientar esa actividad, a regularla o a desarticularla. 
miedo a perder votos aparece como consecuencia de los obstáculos potenciales que puedan oponerse a la oferta de seguridad en los derechos de propiedad que todo Estado hace a sus ciudadanos (D. C. North, 1984). Los partidos políticos deben ser competitivos en el ejercicio de su servicio público, al ofrecer seguridad a cambio de impuestos, para conseguir un bienestar económico que sea capaz de disuadir un desplazamiento del voto hacia sus rivales. Desde esta óptica se respalda la idea de una economía que para los partidos en el gobierno de una nación seguirá siendo siempre, dentro del mundo real, economía política y ese adjetivo -política- generalmente quedará por encima de las preocupaciones estrictamente económicas. Así recuerdo cómo el miedo a una involución política perduraba muchos años después de haber sido perpetrado el asalto golpista del teniente coronel Tejero al Congreso de los Diputados. También recuerdo, del mismo modo, el complejo arrastrado por multitud de españoles desde la era franquista que identificaba un continente africano cuyos límites iniciales estaban ubicados en los Pirineos, según la chanza al uso. La mentalidad del colectivo de políticos refleja siempre la del conjunto de los ciudadanos y por eso consolidar la democracia en nuestro país, primero, y alcanzar después un puesto de pleno derecho entre los europeos como nación, han sido los ejes sobre los que ha girado y a los que quedaban supeditadas el resto de las políticas económicas dictadas desde el Gobierno de la nación. Cuando hubo una oportunidad de homologarse con los europeos, una vez había fallecido Franco, la economía española presentaba tales desequilibrios que era obligado aumentar la demora de los necesarios ajustes (Fuentes Quintana; 1988, 35). El motivo de esta oportunidad perdida estaba sobre todo en la persistencia de la crisis del petróleo.

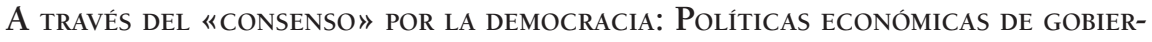 NOS CONSERVADORES Y SOCIALISTAS (1976-1996)}

Los años de la Transición democrática fueron un período de cambio político en España coincidente con una de las crisis económicas más importantes del siglo veinte, la llamada crisis del petróleo. Como afirmaba Julio Segura $(1988,842)$ para la economía española durante la etapa 1974-1982 se produjo un notable retraso en la adopción de políticas activas frente a dicha crisis ${ }^{11}$. La demora en la

11 Señala Segura $(1998,843)$ cómo en 1974 el Gobierno de Arias Navarro estaba gestionando una política puramente compensatoria que trataba de ignorar la crisis. Así en 1975 las políticas fiscal y monetaria tuvieron que ser fuertemente restrictivas, pero aún se mantuvieron la intervención en precios y la contratación colectiva sobre la base de la inflación pasada más un margen. El crecimiento económico se vería resentido cuando se lograba frenar algo la inflación, del 18 al 14 por ciento, pero se incrementaba el paro. 
reacción ante la crisis económica tuvo como primera respuesta la «delirante política compensatoria» de Barrera de Irimo. Fuentes Quintana $(1988,33)$ calificaba así la actuación del ministro de Hacienda, pues dicha política se basó en mantener el precio de la energía, sustituir la menor demanda exterior de las distintas producciones por demanda interna, intervenir ciertos precios para luchar contra la inflación y sobreindiciar los salarios ${ }^{12}$. Los resultados de aquellas medidas fueron, en consecuencia, un déficit en aumento de la balanza de pagos y también del presupuesto, así como un crecimiento de la inflación. Aquella política compensatoria que entre otras cosas hacía caso omiso de la enorme conmoción sufrida por los precios de la energía en el mercado internacional, se dedicaba a subvencionar su consumo interno, y en consecuencia retrasaba dramáticamente los ajustes a la crisis. «La política compensatoria trataba de huir hacia delante ganando tiempo político para un régimen que agonizaba, y a esa pretensión respondieron sus medidas» (Fuentes Quintana, 1988, 34). Hasta los Pactos de la Moncloa, en vigor en 1978, no quedaba demostrada la consciencia de políticos y sociedad sobre las consecuencias de aquella crisis. Según Rafael Myro $(1997,51)$ el crecimiento económico español comparado con el conjunto de países comunitarios experimenta cambios más pronunciados durante el período 1960-1983, pues muestra la profundidad de la crisis y el ajuste ante sus efectos. La renta per cápita crecía al 6,1 por ciento desde 1960 a 1974 y pasa a crecer sólo al 0,5 por ciento hasta 1984. De 1984 a 1993 crecerá al 2,6 por ciento ${ }^{13}$.

Siguiendo el acuerdo más aceptado entre los tratadistas políticos se puede dividir el período durante el que gobierna la UCD en dos partes. Primero, el período anterior a la segunda crisis del petróleo y en segundo lugar, el shock de 1979-1980 y la política económica posterior. Durante el primer período se distingue, una vez formado el nuevo Gobierno, que la coyuntura contiene una inflación con cifras casi «latinoamericanas» (alrededor del 30\%, que según algunos periódicos llegaría al 44\% $)^{14}$. Resulta innegable que una parte del débito contenía una brecha inflacionista, pero también era cierto que en la parte del haber se situaba la claridad de planteamientos de Adolfo Suárez para llevar a cabo la Transición a la democracia ${ }^{15}$. Más adelante resultaría trascendente que durante

12 Se autorizaba el crecimiento de los salarios según la norma de los sindicatos franquistas: inflación del pasado + 2 ó 3 puntos. Véase Fuentes Quintana $(1988,33)$.

13 La pronunciada desaceleración del avance en la renta per cápita se produce alrededor de 1980. Ver Myro $(1997,52)$.

14 Así se suele afirmar y más si el comentario proviene de fuentes periodísticas; ver GámiR/ DURÁ $(2004,97)$ nota 1: crecimientos reducidos del PIB, paro en aumento...

15 Lo cual quedaba articulado en la Ley para la Reforma Política. Véase Linz, Juan (1996, 29). 
esos años se alcanzase la firma de los Pactos de la Moncloa, fase que culminaría en octubre de 1977. Se debe recordar aquí que el cauce final seguido para la consecución de los Pactos fue la vía parlamentaria, es decir que no era un pacto social. Fue por consiguiente un acuerdo más amplio que la idea contenida en el binomio «empresarios-sindicatos», pero Adolfo Suárez decidió dejar a estos últimos fuera del acuerdo, al menos en principio, para lograrlo con celeridad. Por otra parte en los Pactos de 1977 la política de rentas acordada tuvo como artífice a Enrique Fuentes Quintana ${ }^{16}$. Dicha política también contaría con el respaldo de los sindicatos que según Soto Carmona (1996, 397-8) aceptarían, como contrapartida al apoyo económico del Estado, acuerdos neocorporativos como el inicial de los Pactos de la Moncloa, al tiempo que permitieron una creciente flexibilización del mercado laboral ${ }^{17}$.

En los Pactos de la Moncloa se combina las políticas estabilizadoras destinadas a corregir los desequilibrios macroeconómicos -principalmente la inflación-, tales como la Política monetaria, la Política fiscal, o la Política de rentas, con políticas de reformas con mayores efectos y período de implementación. Como de hecho fueron las Políticas arbitradas para lograr la disminución del proteccionismo exterior, la reforma del sistema financiero, o bien la definición de un nuevo marco de relaciones laborales y, además estaba la que acometía la reforma fiscal. La superación de las dificultades económicas, durante un proceso de Transición a la democracia, daba a través de los Pactos de 1977 una respuesta de Estado, no únicamente de partido, a los problemas políticos que la misma originaba. Aquellas medidas de ajuste global o saneamiento pactadas en la Moncloa obtuvieron claros efectos sobre el nivel de precios y el equilibrio de la balanza de pagos ${ }^{18}$.

16 El primer borrador de los Pactos de la Moncloa fue diseñado por el propio Fuentes, que haciendo suyas las palabras pronunciadas por un político de la República en 1932 afirmó: «O los demócratas acaban con la crisis económica española, o la crisis económica acaba con la democracia». Ver Tizón, Álvaro, «Fuentes Quintana, el economista que gestó los Pactos de la Moncloa», E1Mundo, 11/06/2007. Si se compara los Pactos de la Moncloa con un precedente relevante, como el Plan de Estabilización de 1959, huelga decir que la referida política de rentas no estaba presente en dicho Plan. Se puede mencionar también la aprobación del Estatuto de los Trabajadores, vinculado a la política de rentas a través del primer Acuerdo Marco Interconfederal (AMI) de 1980, cit. en GÁmiR $(2004,101)$.

17 Se puede aceptar a UGT y CC.OO. como corresponsables de la política económica del Gobierno, a pesar de quedar excluidos de la firma de los Pactos de la Moncloa. Según explica Soto Carmona (1996, 397, nota 93) Comisiones Obreras tuvo dificultades para explicar su apoyo a los Pactos y justificaba su postura principalmente por el temor a un golpe militar.

18 Una síntesis de las políticas de ajuste a la crisis económica divididas en políticas de saneamiento (ajuste global) y políticas de reformas (ajuste positivo) puede verse en FuENTES Quintana $(1988,43)$. 
Las políticas de ajuste a la crisis -desde los Pactos, en 1977- cuya aplicación se prolongaría en los años ochenta fueron el prólogo obligado para negociar con la CEE y firmar después el Tratado de Adhesión, en 1985. El contenido técnico de los Pactos adelantaba la política de ajustes que la OCDE definiría a partir de 1980. Aquel contenido técnico consensuado en la Moncloa contenía las medidas que se trataron de aplicar en las etapas posteriores, desde el disenso político pero con pactos sociales, al menos hasta 1989, cuando ya España había entrado en la CEE.

¿Qué sucedió con el shock de 1979-1980 y la política económica posterior de la UCD? Cuando se contaba con una mejoría para 1979, surgiría una segunda crisis del petróleo y todas las previsiones tuvieron que ser revisadas a la baja. La economía española sufre este segundo golpe cuando se ajustaba a la crisis anterior (mientras para los países de la OCDE hubo dos años de respiro). No hay en 1979 un shock adicional desde los costes del factor trabajo. No se comete el error de aplazar el ajuste a la crisis, porque las autoridades trasladaron inmediatamente el aumento de los costes del petróleo a los precios internos. Desde el 28 de junio de 1979 cuando la OPEP sube el precio del barril, la reacción del Gobierno español sólo tardaría cuatro días en producirse. La política económica centrista tuvo un período más liberal con el Programa económico del Gobierno (PEG,1979) y otro más intervencionista que se intensifica en $1982^{19}$. Se atisbaba en embrión la denominada Reconversión Industrial, que contenía una política micro y sectorial con el Decreto-ley Bayón (Gámir / Durá, 2004, 101), política que continuaba el Gobierno del PSOE con el ministro de Economía Carlos Solchaga al frente.

Existen luces y sombras acerca de los objetivos conseguidos con las políticas económicas emprendidas. Suele darse una valoración positiva de la política económica de la UCD, amparada en que la herencia recibida era cuando menos muy compleja $\mathrm{a}^{20}$. Al igual que España hizo frente al shock del petróleo de 19731974, ahora se abordaría el nuevo shock energético de 1979-1980, es decir la nueva crisis internacional. Se afrontaría dicha crisis con las herramientas polí-

19 La política económica posterior al shock del 79-80 mantiene el esquema de la política de rentas-política monetaria iniciado ya en los Pactos de la Moncloa y se profundiza en la reforma de los mercados de factores productivos. Quedaba afectada la Política Fiscal, pero también la Política Monetaria y la Política de Rentas, se daba continuación a la Liberalización del sistema financiero y se adoptaba un Plan energético nacional. Véase el desarrollo de GÁmir (2008, 34-37).

20 La inflación galopante rozaba el 30\% y su tendencia era creciente; el paro avanzaba de forma diferente al resto de Europa y la Democracia recién establecida estaba por consolidar. 
tico-económicas disponibles por aquel entonces: Pactos de la Moncloa, Reforma Fiscal y Medidas de Ajuste y Estructurales. Se lograría atajar el shock de oferta de los costes de trabajo, creándose la cultura de la «inflación esperada». Quedaba atrás la indiciación de los salarios y se abría una vía para la moderación salarial que tanto se necesitaba con el fin de reducir la inflación galopante. Se desvió la presión igualitaria del instrumento salarial al fiscal, al tiempo que se introducía un sistema impositivo y de gasto público en línea con Europa. Se redujo la inflación a la mitad y cuando la UCD dejaba el Gobierno se había contenido hasta el 13,2 por ciento ${ }^{21}$. El debate sobre la empresa pública que se había originado en los años sesenta presagiaba y hacía prever la era de las privatizaciones que acaecería durante el siguiente ciclo político económico ${ }^{22}$.

Esa valoración positiva de la política económica durante el mandato de la UCD parece difícil de aplicar al tercer mandato del PSOE cuando Felipe González contaba casi con catorce años de presidente del Gobierno. Veamos ese desempeño del poder por los sucesivos gobiernos socialistas desde 1982 hasta las elecciones de marzo de 1996.

Resultaba aparentemente contradictorio que el grupo socialista propugnase la necesidad de nacionalizaciones por el año 1976 y que sin embargo fuese el partido que iniciaría la era de las privatizaciones en España ${ }^{23}$. Cierto que la política económica del PSOE pudo llegar a ser muy radical, pero al no ganar las elecciones de 1977 el tiempo de la Transición a la democracia actuó a favor de planteamientos socialistas más morigerados ${ }^{24}$. Cabe pensar además que el ejemplo de Francia arrojaba tierra, con el fracaso de la política de nacionalizaciones

21 Haciendo una enumeración sumaria de las principales intenciones así como de ciertos logros se puede afirmar que: se profundizó en la liberalización del sistema financiero; se reguló el mercado de trabajo dentro del contexto político de la época; se fortaleció la política monetaria y se evitó una potencial crisis financiera; se creó un contexto de «consenso» en amplias partes de la política económica, que facilitó una Constitución por consenso, etc., GÁmir (2008, 36-37).

22 Segura (1998, 856 y ss.).

23 Durante el XXVII Congreso del PSOE se aprobó un programa «radical» cuyo ideario ahora parece algo extraño, puesto que suponía el mantenimiento de la propiedad privada sólo para las pequeñas empresas en las que se entremezclaba o confundía la propiedad con la gestión de su actividad. Se apostaba desde postulados marxistas, dentro de una economía planificada, por un programa de nacionalizaciones que afectaría a las grandes empresas industriales y de servicios (banca, eléctricas,...), así como a las agrarias.

24 Son los años de la Transición cuando Miguel Boyer, más tarde ministro de Economía, abandonaba primero el PSOE para integrarse en Centro Democrático, para luego también dejar este partido que se convertía en Unión de Centro Democrático bajo el liderazgo de Adolfo Suárez. El CD estaba integrado por miembros de Alianza Popular y otros de ideología democristiana, liberal y socialdemócrata. 
de Mitterand, a un enfoque económico más radical para aplicar en España ${ }^{25}$. A pesar de ello el programa electoral presentado por el PSOE en 1982 era bastante menos progresista que el aplicado por Boyer en su etapa del primer gobierno González hasta 1985, cuando reorienta la política económica (Decreto Boyer, 30-04-1985 ${ }^{26}$, después de un ajuste que ya le había permitido obtener buenos resultados respecto al consumo y la inversión privados, al empleo y a las reformas institucionales para la integración en Europa.

El PSOE ganaría tiempo durante el período de 1976 a 1982, pues le faltaban esos años para atemperar su radicalismo, tan patente en los postulados marxistas del Congreso de 1976. La política de rentas pactada fue clave, primero para lograr una aproximación de los salarios más bajos a los más elevados, es decir una contracción salarial que la nueva democracia exigía desde las reivindicaciones sindicales, pero también desde los postulados de funcionamiento racional de la economía de mercado. España quedaba definida en la Constitución de 1978 como una «economía social de mercado», y está suficientemente contrastado que los Pactos de la Moncloa avanzaban en la liberalización económica del país (Fuentes Quintana; 1988, 45).

La modificación pactada de la relación entre las subidas salariales y la inflación esperada, dejando atrás el viejo esquema de adaptar esos incrementos a la inflación ocurrida, ayudaría a moderar el ritmo de esa variable ${ }^{27}$. La política

25 Todo porque en 1979, el PSOE -tras no ganar las elecciones-celebra un congreso y abandona el marxismo, que conserva como «método». Es posible volver la mirada para hacerle «preguntas inmorales a la Historia», como habría dicho don Gregorio Marañón. Si nos interrogamos acerca de la motivación más probable para hacer ejercicios académicos contrafactuales, podemos averiguar parte de la respuesta desde el siguiente planteamiento: Si el PSOE hubiera ganado las elecciones de 1977, ¿qué dirección habría tomado la Política Económica española?

26 Se interpreta dicha etapa 1982-1985 como un período de ajuste donde hubo que adaptar la propaganda electoral a los condicionantes de la situación económica heredada: paro creciente (estructural de masas desde 1975 en adelante) y elevada inflación (ambos unidos, elevado paro e inflación galopante, a lo largo de los años setenta se conocieron como stanflación), déficit por cuenta corriente, déficit público en alza y actividad económica ralentizada. Se admite tradicionalmente que el contenido básico de las medidas del Decreto Boyer de 1985 para afectar los grandes objetivos mencionados en el texto, si bien obtuvo escasos resultados fueron decisivos para crear una atmósfera que permitía percibir el final de la etapa de «vacas flacas».

27 Si la elevación salarial coincide con la inflación esperada, en media anual, la cesta de lo comprado durante todo el año subirá igual que los salarios. Con el PSOE la política de rentas se endurece: dicha política utilizará el objetivo «inflación diciembre sobre diciembre» y no la inflación media como se había utilizado en el caso de la UCD. Con el nuevo planteamiento del PSOE el poder adquisitivo de los salarios finalmente se reduce en media anual, ver GÁmir $(2008,38)$ 
monetaria basada en la oferta monetaria experimenta un cambio con el PSOE que supone innovación en los instrumentos financieros, en este caso un agregado monetario más amplio ${ }^{28}$. Se justifica en base a la creciente liberalización de los mercados financieros que implicaba una relación más inestable entre la oferta monetaria y el $\mathrm{PIB}^{29}$. La política fiscal se basaba en un incremento de los impuestos, de la inversión y del Gasto Público, puesto que había acuerdo en las necesidades sociales que estaban sin cubrir adecuadamente. Si algo destaca entre las semejanzas de aumentos en la presión fiscal, déficit y deuda pública entre los alcanzados por la UCD y el PSOE es la diferente proporción en los cambios y su peso relativo, de 1977 a 1986. El aumento del Gasto Público de UCD no tiene el punto de partida que tuvo el PSOE, pues justamente el mayor aumento fue el otorgado al Gasto Público por el primer partido en el Gobierno de la nación ${ }^{30}$.

La gran relevancia pública, dentro de la primera fase del Gobierno del PSOE, por el proceso de reconversión industrial concluye a finales de 1986. Los sectores siderúrgico y naval acapararían el 75 por ciento de las ayudas. Las diferentes valoraciones sobre el proceso, o bien sobre los resultados del mismo, parecen poco halagüeñas. Habiendo sido el coste muy cuantioso parece que salvo para las declaradas Zonas de Urgente Reindustrialización, la política de reconversión se ceñía a planteamientos más defensivos que otra cosa, dejando orillada la idea de promoción industrial. La memoria colectiva retiene percepciones tan claras como poco elogiosas de aquel proceso, como el caso de la región asturiana, donde la equivalencia práctica entre reconversión industrial y concesión de prejubi-

28 En concreto los llamados ALPs. que sustituyen a la M3 después del período transitorio 1983-1984 durante el que se fijaban objetivos para ambos agregados. Este cambio se debía a la creciente liberalización de estos mercados. Las siglas ALP significan activos líquidos en manos del público e identifica una variable que es un agregado monetario denominada así: ALP. Su definición abarca el anterior agregado monetario la M3 a la que se suman los títulos a corto plazo en poder de las familias (T), más los pasivos del sistema bancario (cesiones de activos privados, letras endosadas, avales a pagarés de empresa y seguros realizados por la banca (OPB), más los pasivos de otras instituciones financieras (POI). Ver CuAdRado RouRA (2001, 327).

29 Más concretamente entre la M3 y el PIB nominal. El agregado monetario M3 se define como el M2 más los Depósitos a plazo, que en España se denomina disponibilidades líquidas. El M2 es igual al M1 más los Depósitos de ahorro que el público mantiene en el sistema bancario y el Ml son el efectivo en manos del público más los Depósitos a la vista en el sistema bancario. Ver Cuadrado Roura, ibidem.

30 Un incremento de hasta $1 / 4$ del PIB, mientras durante el PSOE se alcanza el 37\%. De nada al 25\% hay más tramo recorrido que hasta llegar al 37\% desde el 25\% de la época de la UCD, este último incremento supuso sólo el $12 \%$. Aunque parece que ese aumento del gasto público llegaría al nivel del 50\% cuando el PSOE deja el Gobierno, parece lógico destacar que después el reto mayor consistiría en lograr mayor eficiencia en la asignación de ese gasto. 
laciones desvirtuaba la declaración de intenciones gubernamental ${ }^{31}$. Después de ponderar los aumentos de la productividad y la competitividad de los sectores fabriles ligeros que habían redundado en una lógica mejora de esas exportaciones, Fuentes Quintana afirmaba que «la gran industria, la industria básica afín al sector público, ubicada a lo largo de la Cornisa Cantábrica y sometida a planes de reconversión, hace agua por sus cuatro costados» ${ }^{32}$.

Cuando el 1 de enero de 1986 España ingresa en la CEE, se produjo un salto realmente importante en el desmantelamiento del proteccionismo patrio. El período transitorio ${ }^{33}$ exigiría la desaparición de aranceles con socios comunitarios, además de la aplicación de la Tarifa Exterior Común ante terceros países ${ }^{34}$. Un objetivo del Mercado Único era el de conseguir la libre circulación de capitales. España, al final de este período, en diciembre de 1991, sin agotar el plazo, liberalizaba plenamente los movimientos de capital. ${ }^{35}$

Los avatares fueron muchos mientras que los retos planteados ya suponían suficiente esfuerzo para mantener un bienestar económico bajo una continuidad política en democracia. En 1989 el cambio en la orientación de la política fiscal se produjo -para luchar contra la inflación- con parámetros más expansivos que se identificaban con una cierta laxitud fiscal. Las razones para adoptar este tipo de medidas fueron entre otras el éxito de la huelga general de diciembre de 1988, que trajo consigo una fuerte demanda de incremento del gasto público. El consiguiente desgaste político del partido en el poder llevaría a celebrar elecciones generales en el último trimestre de 1989.

La política fiscal expansiva unida a una política monetaria restrictiva, mientras la demanda interna crecía de modo muy intenso, condujo al llamado modelo de los dos déficits (Gámir, 2008). Un déficit con relación al sector exterior de la economía y el otro déficit respecto al originado por el sector público. Desde

31 Se entiende que el proceso para abordar la supuesta tarea de «reconvertir» fue un fracaso. Aquella «reconversión» afectó a unos 84.000 trabajadores y tuvo un coste aproximado de 1,5 billones de pesetas, como coste estimado para Sector Público al final de 1989. Ver Leboutte (1997, 485-488).

32 Añadía también Fuentes Quintana $(1988,67)$ que «El ajuste efectivo de la economía española pasa por la reconversión de las empresas y los sectores obsoletos». Una visión de la política industrial europea y la desindustrialización en perspectiva histórica puede verse en ForEMAN-PECK (1998, 177-193).

33 Incluido en el Tratado de Adhesión coincidirá con la formación del Mercado Único (1993).

34 Por término medio la Tarifa comunitaria resultaba más reducida que la española.

35 Dicha liberalización se daría con los países de la UE y también con el resto del mundo. La repercusión en el aumento del comercio de bienes y servicios respecto al PIB supuso de 1999 a 2006, un crecimiento del 5,79 por ciento. Ver cuadro de Muñoz Cidad (2008, 54). 
1990 el déficit público empezaba a crecer y se volvía impredecible por el bajo grado de cumplimiento de los presupuestos ${ }^{36}$.

Hay que tener en cuenta que ya pertenecíamos a un Sistema de Cambio Fijo desde 1989, el Sistema Monetario Europeo (SME). Dicho SME gozaba de cierta credibilidad en el mantenimiento de las paridades centrales. Por consiguiente al subir el precio del dinero y pertenecer al SME se produjo una fuerte entrada de capitales. Pero la apreciación de la peseta ${ }^{37}$, unida al diferencial de inflación supuso una pérdida de competitividad de nuestros productos ${ }^{38}$. El resultado no podía ser otro, al mermar las exportaciones, que un elevado déficit de la Balanza de Pagos por cuenta corriente. Obtuvimos el dudoso honor de alcanzar un record -España, 1990- dentro de la OCDE, con un déficit del 3,7 por ciento del PIB. Pero se avecinaban tiempos difíciles, la recesión de 1992-1993 era más profunda en España que en la Unión Europea, y una de las más severas, aunque no de las más largas. Durante dicha crisis económica se asistiría a varias devaluaciones de la peseta que conseguirían paliarla en gran medida ${ }^{39}$. Nuestro país pasaba de tener una moneda artificialmente fuerte, en septiembre de 1992, a verse obligada a una primera devaluación de la peseta (un 5 por ciento). Las medidas que acompañaron la devaluación no fueron adecuadas, por lo cual se produjo una de las peores situaciones: se devaluaba nuestra divisa y se dejaba la moneda bajo sospecha de una nueva devaluación. En octubre de 1992 el diferencial de los tipos de interés a largo plazo con Alemania siguió incrementándose, y superó los 5 puntos (septiembre de 1992, devaluación) para llegar hasta los 5,64 puntos. Los mercados seguían apostando por una nueva devaluación. En noviembre de 1992 la peseta tuvo que ser devaluada de nuevo, ahora un 6 por ciento, y el diferencial empezó a disminuir pero al final de año aún estaba por encima de los 5 puntos. En mayo de 1993 faltaban medidas de acompañamiento y era preciso devaluar por tercera vez en menos de 1 año, ahora un 8 por ciento ${ }^{40}$. Aunque la tercera modificación del tipo de cambio frenaba las devaluaciones en cadena,

36 Se alcanzan desviaciones significativas sobre el gasto presupuestado inicialmente, para niveles muy elevados, como nos muestra los siguientes datos (BAREA, 1995):

$1989 \quad 32 \%$

$1990 \quad 25 \%$

$1991 \quad 22 \%$

37 La moneda más fuerte del SME (1990-1991); estaba situada en la parte alta de la banda.

38 Disminuye el peso de las exportaciones y se aceleran las importaciones.

39 Cuando Dinamarca rechaza en referendum el Tratado de Maastrich disminuirá la credibilidad del SME y los mercados se centraron en las monedas de países con políticas inconsistentes con mantener un tipo de cambio fijo, por ejemplo, España.

40 Según algunos analistas: con esta devaluación la peseta recuperaba el tipo de cambio teórico que le correspondería si se le aplicase la teoría del poder de compra. 
menos de dos años después, en febrero de 1995, sobrevendría la cuarta devaluación de la peseta, un 8 por ciento ${ }^{41}$.

\section{En la Senda de CONVERgencia: Políticas eCONÓmicas de GObieRnos SOCialistas Y CONSERVADORES (1993-2006)}

Uno de los significados de la globalización se comprueba, generalmente, con la convergencia de los valores de las principales variables económicas. Para España pasar a integrar un ente supranacional como el de Europa supuso también globalizarse más aprisa, pues el Tratado de Maastricht contenía unos criterios de convergencia nominal para formar parte de la Unión Monetaria Europea (UME). En 1995 se celebra el Acuerdo de Madrid sobre la denominación del euro como la moneda única y, por entonces, parecía casi imposible que España pudiera integrarse dentro del plazo. Pero en 1998 quedaron fijadas las paridades irrevocables para las monedas de los 11 países que cumplían los criterios según el Consejo de Asuntos Económicos y Financieros (ECOFIN) y el Consejo Europeo de mayo del susodicho año. Como es bien conocido España hizo el acuerdo según el cambio fijo de 1 euro por 166,386 pesetas.

El Tratado de Maastricht, aprobado en diciembre de 1991, tras un largo proceso de ratificación, entra en vigor en noviembre de 1993 dando paso a la transformación de la Comunidad Económica Europea (CEE) en la Unión Europea (UE). El Tratado de la Unión Europea enmarcará el desarrollo de nuestra política económica en toda la década de los noventa. En el Tratado de Maastricht se fijaban los criterios de convergencia necesarios para poder formar parte de la moneda única. Ya antes de entrar en vigor Maastricht se convierte en referencia fundamental de la política económica. Si en los años setenta se afirma ya que con la crisis energética el Estado del Bienestar hace agua, la idea es reiterativa cuando se implanta Maastricht pues incide seriamente en nuestra economía la crisis de $1992^{42}$.

En marzo de 1992 el Gobierno español aprueba el Programa de Convergencia que definía las líneas básicas de la política económica para 1992-1996. Dicho programa contenía previsiones diferentes a las de los presupuestos aprobados unos meses antes e incluso éstas quedarán también desbordadas por los hechos.

41 Precedida de continua subida del diferencial de tipos de interés a largo plazo con Alemania [2,3 puntos; enero de 1994 / subiría hasta 4,3 puntos, enero de 1995]. El diferencial superaría los 5 puntos en marzo y después empezaría a disminuir (en 1995 alcanzaría una media anormalmente elevada: 4,4 puntos). Sólo desde finales de año, después del anuncio de elecciones adelantadas, se produce una reducción significativa de la prima de riesgo: pasando de 4,2 puntos; en noviembre de 1995 a 2,9 puntos; en abril de 1996.

42 Véase Velarde Fuertes $(1993,464)$. 
Algunas medidas de política económica se incumplieron rápidamente, pues aunque no se aumentaba la presión fiscal individual, unos dos meses más tarde el incremento del impuesto sobre la renta de las personas físicas (IRPF) era calificado retroactivamente y también aumentaron las retenciones a cuenta de dicho impuesto, así como el impuesto sobre el valor añadido (IVA). Aquel Programa de Convergencia aprobado tendría escasa trascendencia práctica. Cuando en julio de 1994 entraba definitivamente en vigor el Tratado de Maastricht, se presentaría una actualización del Programa de Convergencia (1994-1997) ${ }^{43}$.

Durante 1991-1993 no se realizaban avances en la convergencia y, con la única excepción de lo ocurrido con los tipos de interés, se produce un empeoramiento en todos los criterios adoptados. A mediados de 1994 ya se hacía necesario actualizar el Programa de Convergencia, dada la disparidad entre sus objetivos y la realidad ${ }^{44}$, por lo cual en julio de 1994 se aprueba una Actualización a dicho Programa de Convergencia, con nuevas previsiones y objetivos hasta 1997.

\section{CUMPLIMIENTO DE LOS CRITERIOS DE CONVERGENCIA}

\begin{tabular}{|c|c|c|c|c|c|}
\cline { 4 - 6 } \multicolumn{1}{c|}{} & \multicolumn{2}{c|}{} & \multicolumn{2}{c|}{ Tipo de cambio } \\
\cline { 2 - 6 } & Inflación & $\begin{array}{c}\text { Tipos de } \\
\text { Interés }\end{array}$ & $\begin{array}{c}\text { Déficit } \\
\text { sobre PIB }\end{array}$ & $\begin{array}{c}\text { Deuda } \\
\text { sobre PIB }\end{array}$ & $\begin{array}{c}\text { N. }{ }^{\circ} \text { de meses } \\
\text { en el SME sin devaluación }\end{array}$ \\
\cline { 2 - 6 } & $\begin{array}{c}\text { Converg. (+) } \\
\text { o diverg.(-) }\end{array}$ & $\begin{array}{c}\text { Converg. (+) } \\
\text { o diverg (-) }\end{array}$ & $\begin{array}{c}\text { Converg. (+) } \\
\text { o diverg.(-) }\end{array}$ & $\begin{array}{c}\text { Converg. (+) } \\
\text { o diverg.(-) }\end{array}$ & $\begin{array}{c}\text { Converg. (+) } \\
\text { o diverg.(-) }\end{array}$ \\
\hline 1991 & $-1,5$ & $-1,7$ & $-1,5$ & 14,5 & 7 \\
\hline 1992 & $-2,1$ & $-1,0$ & $-1,1$ & 12,0 & -23 \\
\hline 1993 & $-1,7$ & $-0,7$ & $-4,0$ & 0,0 & -17 \\
\hline 1994 & $-1,3$ & $-0,6$ & $-3,3$ & $-2,6$ & -3 \\
\hline 1995 & $-2,0$ & $-1,6$ & $-1,3$ & $-5,5$ & -2 \\
\hline 1996 & $-1,1$ & 0,4 & $-1,6$ & $-10,1$ & 10 \\
\hline 1997 & 0,8 & 1,6 & 0,4 & $-8,8$ & -14 \\
\hline
\end{tabular}

Fuente: Banco de España (Boletín estadístico), Programa de Estabilidad 19982002 y elaboración propia, cit. en Gámir $(2008,43)$

43 El déficit de 1993 y el incluido en los presupuestos para 1994 se encontraban muy alejados de lo previsto en el Programa de Convergencia aprobado en marzo de 1992.

44 Como nos señala Gámir $(2008$, 42), el déficit de 1993 y el incluido en los presupuestos para 1994 se encontraban muy alejados de los previstos en el Programa de Convergencia aprobado en marzo de 1992. 
La actualización al Programa de Convergencia de Julio de 1994 contenía dos vertientes significativas. Por una parte se trataba de un programa realizado sobre previsiones macroeconómicas más realistas y, por otro lado, tenía el inconveniente de retrasar los ajustes dejándolos para los últimos años de vigencia, es decir para 1996 y 1997. Para el año 1994 se avanza en la convergencia en casi todos los criterios, con la única excepción referida al criterio de la deuda. Como se puede observar el déficit previsto para 1995 era casi del 6 por ciento, el doble del límite de Maastricht. Pero el déficit real alcanzado fue mayor, (un 7,3\%) como refleja la divergencia del cuadro anterior para dicho año. El año de1995 sería el último año completo de esta fase del PSOE, un año perdido para la convergencia porque se produce un retroceso en los 5 criterios: se empeora en precios, en tipos de interés, en déficit, en deuda y en tipos de cambio (devaluación).

El resultado de 1995 suponía que España se encontraba peor en el último año de Gobierno del PSOE que en el momento de la aprobación del Tratado de Maastricht, 1991. Entre esas fechas se produce un empeoramiento en cuatro de los cinco criterios de convergencia y sólo tiene lugar un avance muy ligero en uno de ellos, el de los tipos de interés [ver cuadro anterior]. Se hace preciso apuntar que desde Maastricht, se supeditaría la política económica al cumplimiento de esos cinco criterios que aparecen en los cuadros precedentes.

El sustituto de Carlos Solchaga en el área económica, Pedro Solbes, después de las elecciones de 1993 adoptaba un cambio de estrategia para permitir el cumplimiento de los requisitos fijados por Maastricht en el plazo previsto hasta 1997. Los registros más pobres de los 14 años de gobiernos socialistas se dieron en esta tercera legislatura ${ }^{45}$, con dos hechos externos que condicionaron estos resultados tan negativos: por un lado, los problemas para la antigua República Federal Alemana (RFA) con la reunificación después de la caída del muro de Berlín y por otro, la «Guerra del Golfo» que introdujo incertidumbre y expectativas negativas. Los modestos resultados, pese a la reorientación de la política económica que pergeñara el ministro Solbes, así como el severo deterioro de la imagen política del último Gobierno socialista lograrían aunar las circunstancias suficientes para un cambio de Gobierno. Éste se produjo el 1 de marzo de 1996, con José María Aznar, presidente del Partido Popular (PP) cuyo mentor era Manuel Fraga Iribarne, que ganaría las elecciones generales pero sin alcanzar la mayoría absoluta.

45 Estos resultados negativos fueron principalmente los siguientes: 1) el crecimiento cayó hasta tasas negativas en los trimestres previos a las elecciones de 1993; 2) el paro repuntaría hasta tasas cercanas al $22 \%$ y 3) sólo la inflación -dentro de un contexto recesivo-, se redujo hasta un $4,5 \%$. 
La directriz más clara del planteamiento económico del PP fue el logro de la consolidación fiscal y la liberalización económica, para conseguir cumplir con los criterios de convergencia de Maastricht. El PP aprovechó la corrección final de la etapa socialista para culminar sus seis primeros meses de Gobierno con unos excelentes resultados en las 3 variables fundamentales: crecimiento, desempleo, e inflación; y así seguidamente en los resultados del primer mandato ${ }^{46}$. Además de esos resultados que posibilitaban la integración de nuestro país en la UME, desde el principio, la economía española quedaba ubicada en un contexto macroeconómico que puede catalogarse como el más favorable de todo el período democrático ${ }^{47}$. Mientras que la incorporación desde el inicio a la UME parecía inasequible al comienzo de la legislatura, resultaría un hecho sin precedentes en la historia económica más reciente de España.

El pilar más importante de la política económica del PP había sido la utilización de una politica de consolidación fiscal sobre tres ejes básicos: 1) una forma de presupuestar estricta; 2) el refuerzo de la presencia del poder ejecutivo en las distintas fases del ciclo presupuestario y 3) la puesta en práctica de las reformas estructurales en áreas estratégicas. El segundo mandato del Gobierno del PP -con mayoría absoluta- trae una clara línea continuista del anterior, reforzando aún más la primacía de la estabilidad presupuestaria ${ }^{48}$. En conjunto es el mantenimiento de una fase económica buena y unos resultados cuyos promedios representan las cifras más favorables de los treinta años de democracia, desde 1977. En las elecciones generales de marzo de 2004 se produjo un cambio de Gobierno, subiría al poder el Partido Socialista Obrero Español (PSOE) con José Luis Rodríguez Zapatero al frente y volvía Pedro Solbes como vicepresidente del área económica. La orientación económica del gobierno Zapatero se caracterizaría por la inexistencia de cambios significativos. La continuidad aparece como la opción más plausible porque en el juego de las herencias políticas no era sensato ninguna ruptura.

La orientación económica del gobierno Zapatero ya había empezado con la herencia del presupuesto presentado en su día por el PP; así como su planteamiento global de política económica ya había sido presentado en la actualización

46 Todo ello posibilitaba que España formase parte de la Unión Monetaria Europea (UME) desde su inicio.

47 De hecho se concitaba en dicha legislatura: un crecimiento económico alto y estable; la reducción del desempleo; y la estabilidad de precios.

48 El Gobierno del PP actuaría de aquel modo para garantizar el equilibrio de las finanzas públicas más allá de Maastricht, en el contexto de una Unión Monetaria. Pero los resultados globales de las tres variables: menor tasa de crecimiento; un ligero incremento de la inflación; pero una notabilísima reducción del desempleo (aproximadamente del 10\%). 
del Programa de Estabilidad 2003-2007. Desde la preparación de los presupuestos de 2005 la política económica socialista se instrumentaba -además de en los presupuestos aprobados en 2005, 2006 y 2007-, en 2 pilares básicos: 1) El Plan de Dinamización de la Economía e Impulso de la Productividad -PDEIP, de marzo de 2005, y 2) El programa Nacional de Reformas -PNR, de octubre de 2005 ${ }^{49}$. La actualización del Programa de Estabilidad 2005-2008 confirmaba la línea continuista en política macroeconómica.

Aquel Programa de Estabilidad 2005-2008 (presentado a finales de 2005) planteaba tres prioridades básicas: 1. Refuerzo de la estabilidad presupuestaria, acorde con el Pacto de Estabilidad y Crecimiento (PEC), reformado tras duro debate con la Comisión Europea, Alemania y Francia, después de los incumplimientos en materia de déficit público de estos países y la inobservancia de las recomendaciones de la primera. 2. La mejora del entorno competitivo e impulso a la productividad en el horizonte temporal 2005-2010, apoyado en los planes PDEIP y PNR. 3. Lograr una mayor transparencia y calidad del marco regulador.

\section{ESPAÑa yA ESTÁ DENTRO de EUROPA....ERGO CONVERGE}

La existencia de una continuidad en la política económica quedaba exigida por la pérdida de soberanía que entrañaba nuestra dependencia, primero de un inexorable proceso mundial de globalización, así como por nuestra integración en Europa. Después de la conflictividad social culminada en la huelga general de 1988 y la consiguiente ruptura con los sindicatos, sobresale como característica

49 El Plan de Dinamización de la Economía e Impulso de la Productividad -PDEIP, marzo de 2005-. La estrategia de aumentar la productividad y el empleo se fundamenta en incentivar la inversión privada en capital físico, humano y tecnológico e impulsar el espíritu emprendedor, en la orientación de las finanzas públicas a la inversión productiva y finalmente en la mejora de la eficiencia del sector público y sus servicios. El Programa Nacional de Reformas -PNR, octubre de 2005- se presentó con 2 objetivos fundamentales: Alcanzar en 2010 la renta promedio de la Unión Europea (UE) y superar en 2010 la tasa de empleo de la UE. Los dos objetivos del Programa Nacional de Reformas se concretaron en los siguientes objetivos específicos para 2010: 1) Reducir la relación Deuda Pública/PIB hasta el 34\%; 2) Aumentar la red ferroviaria hasta los 35 km/ 1000 km2; 3) Disminuir la tasa de accidentalidad en carreteras en un 40\%; 4) Reducir hasta el 15\% la tasa de abandono escolar prematuro; 5) Duplicar la inversión en I+D hasta el 2\%; 6) Converger con la Unión Europea en Sociedad de la Información; 7) Mejorar la posición española en los indicadores de competencia; 8) Aumentar la tasa de actividad femenina del actual 48\% al 57\%; 9) Reducir la tasa de siniestrabilidad laboral; 10) Reducir la tasa de desempleo juvenil hasta el actual 18,6\% del promedio europeo; 11) Aumentar la creación de empresas en un 25\% mediante el fomento de la empresarialidad, especialmente entre jóvenes y mujeres; 12) Aumentar la eficiencia energética y reducir las emisiones de $\mathrm{CO} 2$. 
una laxitud fiscal patente hasta que desde 1990 la economía española como el resto de la europea entraba en recesión. El segundo mandato de Felipe González, después del ajuste económico a la crisis de los años setenta, aplicado en la primera legislatura socialista, ciertamente entronizó a España en la Comunidad Económica Europea (CEE).

España crece más que Europa desde 1994 hasta 2007 y entre los países occidentales del cuadro reconstruido por Gámir $(2008,472)$ en base a la base de datos Eurostat divididos en cuatro períodos, sólo es superada por Irlanda, Luxemburgo y Grecia. Los cuatro que más crecen: Irlanda, Luxemburgo, Grecia y España no presentan muy buenos datos de I+D, crecían por otros factores, shocks de demanda, etc. El modelo de crecimiento español era trabajo intensivo: parados que pasan a empleados, población en edad de trabajar que se incorpora al Mercado de Trabajo, e inmigrantes regularizados, en 1995 unos 540.000 inmigrantes; y en 2006 unos 4.150.000 inmigrantes.

Desde los años noventa del siglo veinte se produjeron en el crecimiento real del producto interior bruto (PIB) espectaculares resultados para Estonia y Letonia que nos muestra el siguiente cuadro, así como los obtenidos para el PIB también por Lituania, Bulgaria y Eslovaquia (5,1\%). Hay países del Este que lanzan su crecimiento, si bien la media de la Unión Europea (UE, 27 países) está sólo muy ligeramente por encima de la UE (15 países); la diferencia es mayor sobre la zona euro. Resulta fácil interpretar este tipo de evolución pues queda referida a las proporciones del crecimiento en las primeras etapas del mismo para esos países. Dicho de otro modo, cuando se parte de niveles muy bajos en la actividad económica, el crecimiento conseguido al principio arroja unos porcentajes de incremento sobre los niveles precedentes muy elevados. Ése es el caso de los países del Este recientemente incorporados a la Unión Europea. Este motivo permite afirmar a Carreras y Tafunell $(2004,465)$ que para España la convergencia se produciría inevitablemente el 1 de mayo de 2004, con el ingreso de los diez nuevos socios comunitarios ${ }^{50}$.

50 Como dichos países son netamente más pobres que la media, rebajarán ésta y elevarán automáticamente la posición española. La referencia de convergencia la hacen los autores y lo explicitan respecto a los países de la Europa Occidental de los que tratan en el libro. Ver CarReras/Tafunell (2004, 465). 
CRECIMIENTO REAL DEL PIB (\% DE CRECIMIENTO SOBRE EL AÑO ANTERIOR)

Tasas medias de crecimiento anual

\begin{tabular}{|lcccc|}
\hline & $2000-2007$ & $1996-2003$ & $2004-2007$ & $1994-1995$ \\
\hline UE (27 países) & 2,3 & 2,3 & 2,6 & -- \\
\hline UE (25 países) & 2,3 & 2,4 & 2,5 & -- \\
\hline UE (15 países) & 2,2 & 2,3 & 2,4 & 2,7 \\
\hline Área euro & 2,0 & 2,2 & 2,2 & -- \\
\hline Bulgaria & 5,5 & 1,3 & 6,3 & 2,4 \\
\hline Estonia & 9,0 & 6,7 & 9,6 & 1,5 \\
\hline Irlanda & 5,8 & 8,0 & 5,3 & 7,8 \\
\hline Grecia & 4,3 & 3,9 & 4,1 &.. \\
\hline España & 3,6 & 3,7 & 3,6 & 2,6 \\
\hline Letonia & 8,7 & 6,1 & 10,2 & 1,3 \\
\hline Lituania & 7,3 & 5,9 & 7,6 & $-2,5$ \\
\hline Luxemburgo & 4,8 & 4,9 & 5,3 & 3,8 \\
\hline Portugal & 1,4 & 2,8 & 1,3 & -- \\
\hline Reino Unido & 2,7 & 2,9 & 2,7 & 3,6 \\
\hline Estados Unidos & 2,6 & 3,2 & 3,0 & 3,3 \\
\hline Fuente: Eurostar & & 6 & $470)$ & \\
\hline
\end{tabular}

Fuente: Eurostat, extractado del cit. en Gámir (2008, 470).

El cuadro anterior permite profundizar respecto al crecimiento económico, en lo ocurrido en los períodos del PP y del PSOE. El crecimiento es ligeramente superior durante el período 1996-2003 que en 2004-200751. La comparación con Europa para el período 1996-2003 puede sintetizarse como sigue: La tasa media de crecimiento anual real del PIB de España, durante ese período, fue 1,4 puntos superior a la experimentada por la UE (27); asimismo y para ese período la misma tasa media resultó 1,3 puntos superior a la de la UE (25); y también del mismo modo superaría en 1,4 puntos al alza a la de la UE (15) y finalmente dicha tasa media de crecimiento anual real del PIB sería 1,5 puntos más elevada que la obtenida por el conjunto de la zona euro (ver cuadro previo).

51 La adjudicación -datos anuales de Eurostat- de los años de cambio es al partido que estuvo más tiempo en el Gobierno en dicho año. Así nos lo aclara el autor, Gámir (2008, 470), 
Las herencias para los partidos que se alternaron en el Gobierno de la nación, recibidas del mandato que les precede, deben asumirse como algo consustancial al desarrollo de la economía política del país. Así dentro del largo período considerado cuando el PSOE empieza a gobernar en 2004 parece innegable que contaba con una buena herencia del período anterior, bajo el mandato de Aznar, 1996-2003. Sin embargo el PP en 1996 había tenido mucha peor herencia del PSOE, 1994-1995, que terminaba de capear la crisis de los noventa gracias a las cuatro devaluaciones de la peseta de Solchaga y Solbes. ${ }^{52}$.

Los datos de crecimiento del PIB real que muestra el siguiente cuadro permiten comparar de una forma más precisa, a la vez que resultan más fiables puesto que se mide dicha evolución respetando la paridad del poder adquisitivo de cada divisa. Si nos fijamos en esas cifras y tomamos como base la «Europa 27 países», España pasaba de un crecimiento real del PIB per cápita del 92,1 en 1995 al 103,9 en 2007. Aún lejos de la «Europa 15 países», sí se reducen distancias respecto a ese agregado porque España pasaba de un crecimiento real del 80\% al 89\%, entre 1996 y 2003. Es decir, se había producido un incremento del 11\%, en 2 legislaturas ${ }^{53}$. Otra dimensión de análisis consistiría en la descomposición sectorial de ese producto interior bruto, para comprobar si el avance proporcionado en aras de nuestra integración europea forjaba la base que mejor orientaba el futuro económico de la nación, o bien estaba fraguado por intereses partidistas.

52 No se incluye el año 1993 porque forzaría la comparación, incluso su introducción parcial reduciría la tasa de crecimiento del último Gobierno del PSOE, antes de la victoria del PP en 1996. En cualquier caso el crecimiento durante 1994-1995 es menor al europeo y la diferencia es mayor si introducimos parte de 1993. Ver GÁmir $(2008,471)$.

53 Portugal no acorta distancias, mientras España y Grecia «sí». Los países del Este avanzan pero no tanto como Estonia. Grecia mejora... Irlanda: de estar por debajo de la UE (15), en 1995 a quedar por encima. Estonia duplica su porcentaje respecto a la UE (27), y sigue bastante alejada... Luxemburgo lleva a cabo un «rápido camino hacia delante» [en 2007 logra una renta per cápita un 88 por ciento superior a la de EE.UU.]. Alemania: pasaba de estar muy por encima de UE (15), a colocarse casi a su altura. 
PIB PER CÁPITA EN PARIDAd DE PODER ADQUISITIVO (EU27 = 100)

\begin{tabular}{lcccccccc}
\hline & 1995 & 1996 & 2000 & 2003 & 2004 & 2005 & 2006 & 2007 \\
\hline UE (27 países) & 100 & 100 & 100 & 100 & 100 & 96,1 & 96,2 & 100 \\
\hline UE (25 países) & 104,8 & 104,8 & 105 & 100 & 104,2 & 100 & 100 & 103,9 \\
\hline UE (15 países) & 116 & 115,6 & 115,2 & 108,9 & 113,1 & 108,2 & 107,8 & 111,8 \\
\hline Área euro & 117,7 & 116,8 & 115,6 & 107,3 & 111,1 & 106,1 & 106 & 109,9 \\
\hline Estonia & 36 & 37,5 & 44,8 & 51,1 & 57 & 59,7 & 64,7 & 72,5 \\
\hline Irlanda & 103,2 & 108,5 & 131,2 & 134,3 & 142,4 & 138,5 & 138,6 & 143,8 \\
\hline Grecia & 75,5 & 75,1 & 77 & 80,1 & 84,9 & 83,9 & 85,2 & 89,5 \\
\hline España & 92,1 & 92,6 & 97,8 & 96,6 & 100,9 & 97,7 & 98,2 & 103,1 \\
\hline Luxemburgo & 223,8 & 222,2 & 244,7 & 236,4 & 252,7 & 250,5 & 268,3 & 283,9 \\
\hline Portugal & 75,3 & 75,5 & 78,3 & 73,4 & 75,2 & 71,5 & 71,8 & 74 \\
\hline Reino Unido & 112 & 114,1 & 117,4 & 116,8 & 121,8 & 118,1 & 114,6 & 119,4 \\
\hline Estados Unidos & 158 & 158,6 & 159,5 & 146,1 & 153,5 & 149,6 & 147,9 & 151 \\
\hline
\end{tabular}

Fuente: Eurostat. extractado del cit. en Gámir (2008, 472)

A la vista de los cuadros precedentes se debe tener cuidado con la interpretación de los resultados, pues nada más cierto que: «cada uno juega con las cartas que le han repartido». Así sucedía en la España del período considerado como en cualquiera otra nación democrática, los partidos políticos jugarán su mano, su mandato en el poder, más o menos extenso, con las cartas que les habían tocado en suerte.

Las peculiaridades de la situación española siguiendo lo argumentado por Torres Mancha $(2008,109)$ pueden resumirse en dos: 1) los graves efectos económicos de la crisis de los setenta, coincidiendo con un complejo proceso de cambio político -y la necesidad de política económica de ajuste duro-: los problemas económicos se supeditan a iniciar la andadura democrática y a consolidarla (la evolución de los principales objetivos de política económica así lo evidencia); 2) la incorporación española a Europa y la intensificación de los procesos de integración económica ( $1 .^{\circ}$ Mercado Único y 2. ${ }^{\circ} \mathrm{UME}^{54}$ ) determinaron el funcionamiento de la política económica (ajuste a normas impuesta desde fuera), por lo que los gobiernos han tenido escasas o nulas posibilidades de aplicar políticas económicas partidistas o electoralistas. Pero se debería añadir una tercera característica, que ciertamente está supeditada a la segunda ya mencionada: la apertura de la economía española conseguida a través de la liberalización comercial

54 Desde 1999 la política monetaria y el control del tipo de cambio pasan al Sistema Europeo de Bancos Centrales SEBC (inflación: 2\%). 
derivada de la integración en Europa. Dicha apertura se aceleraba conforme lo hacía el proceso de globalización desde los años noventa. ${ }^{55}$

Aproximadamente un año después de que, en Estados Unidos, se declarase la crisis de las hipotecas «subprime» ${ }^{56}$, se vivía ya en España por noviembre de 2008 un ambiente cuajado por la receptividad de la clase política a la situación real de la economía del país. La aceptación de la existencia de recesión en la eurozona traía consigo en titulares periodísticos el asentimiento a la existencia de una contracción de la economía española, por primera vez en los últimos quince años. A la vez que la vicepresidenta De la Vega aceptaba que la situación empeoraría. La herencia política acumulada y la incidencia de la crisis financiera internacional condicionaban seriamente las decisiones del ejecutivo. Pero para llegar a ese punto hay que recorrer la etapa que se trata aquí y la finalidad declarada para el ejercicio académico propuesto es concluir sobre quién lo hizo mejor, o quién obtuvo mejores resultados administrando lo público, desde la Transición democrática hasta 2006.

\section{¿Qué Partido político administró mejor lo Público? Objetivos y debates}

Además del debate suscitado durante el mandato de la UCD sobre el Estado de las Autonomías, bajo el gobierno de Adolfo Suárez, hubo otro debate cuya dialéctica dejó una profunda huella, tanto política como económica: el debate sobre las privatizaciones. El acento que los gobiernos pusieron en las políticas de oferta, frente a los intentos por modular la demanda agregada, se importaba de las prácticas que tanto en Inglaterra como en Estados Unidos habían adoptado Margaret Thatcher y Ronald Reagan. Aquellas prácticas recibieron el lógico calificativo de antikeynesianas, que, como es de sobra conocido, tuvieron muchos seguidores. En España también se decidió privatizar empresas públicas desde el primer mandato de Felipe González, aunque las privatizaciones más conocidas se darían más tarde durante el Gobierno de José María Aznar ${ }^{57}$. La nueva política

55 El índice de apertura de una economía se mide normalmente por la ratio de la suma de exportaciones más importaciones de bienes y servicios respecto del PIB del país. Entre 1993 y 2000 dicha ratio pasaba del 44\% del PIB al 61\% del PIB, aunque esta apertura ha disminuido en los últimos años. Ver De la Dehesa $(2007,413)$. Debido a nuestro elevado desempleo y a la volatilidad del crecimiento económico la convergencia real en términos de renta per cápita parece menor que en países como Irlanda y Portugal (De La DehesA, 2007, 445-6).

56 Se denominan hipotecas «prime» aquellas que tienen poco riesgo de impago y «subprime», aquellas que tienen más riesgo de impago.

57 Ya desde 1994 la política de privatizaciones empezaba a contemplarse desde una perspectiva más amplia. El propio Ministerio de Industria propondría que las privatizaciones fueran utilizadas como un instrumento de la propia politica industrial, es decir que dejaban 
concerniente a las privatizaciones se había consolidado cuando España accedía a la Comunidad Económica Europea, en 1986, pero se debe apuntar que no seguía un plan organizado.

La estrategia política del programa de privatizaciones tenía como primer objetivo promover la reconversión industrial, mientras el segundo objetivo en importancia era de carácter financiero. Este último se centraba en conseguir ingresos extraordinarios para eliminar los déficits presupuestarios para, en consecuencia, poder reducir los subsidios a las empresas deficitarias y lograr así que se autofinanciaran. ${ }^{58}$ La llegada, en 1996, del Partido Popular al poder no sólo cambiaría con sus privatizaciones totales el grado del proceso privatizador, sino también el enfoque ideológico del mismo. El pensamiento básico residía en la creencia de que las empresas públicas se convertirían en más eficientes, desde el momento en que se entregaban a la gestión de la iniciativa privada.

Según Clifton, Comín y Díaz (2003, 74), la idea del Partido Popular era que no tenía sentido en la economía globalizada y, por ende, en el proceso de integración de la Unión Europea, mantener un sector de empresa pública y por consiguiente era preciso desmantelarlo. Algo problemático como consecuencia de la total privatización de la época del PP fue que el sector de las empresas públicas casi desapareció en todas las áreas en las cuales su presencia había sido clave, tales como las telecomunicaciones, electricidad, petróleo, gas natural y siderurgia. Sin embargo el resultado último conseguido era que los monopolios públicos habían sido reemplazados por monopolios privados que eludían la competencia efectiva. Este tipo de problema constituía un desafío para el Gobierno que quería mantener una competencia real en esos sectores de actividad, para lo que legislaba en consecuencia. Parece incuestionable que precisamente la privatización supuso un punto de inflexión en la evolución del poder empresarial en España ${ }^{59}$.

Al mencionar la globalización de la economía se plantea directamente el

de ser, por ejemplo, un objetivo de carácter financiero. Ver Clifton, Comín y Díaz (2003, 72-76).

58 Se liquidaron empresas que no se consideraban de interés estratégico, como fue el caso de renombradas empresas turísticas, tales como la agencia de viajes más antigua de España, Viajes Marsans, o también Entursa. Ver CAses, Pedro, El País, 11/06/1985: «El Ministerio de Industria y Energía defiende que la permanencia en el INI de la cadena hotelera Entursa y la agencia de viajes Marsans no tiene sentido, por cuanto no las considera empresas estratégicas. Transportes, Turismo y Comunicaciones, sumamente molesto por no haber sido oficialmente informado de los pasos que se están dando para su privatización, es partidario de mantener Entursa y Marsans en el sector público, ligados al futuro Inprotur, de modo que el Estado pueda hacer una oferta de calidad en el sector turístico, al que considera estratégico».

59 Véase Clifton, Comín y Díaz (2003, 75).

Pasado y Memoria. Revista de Historia Contemporánea, 9, 2010, pp 65-100 
debate del margen de maniobra de las políticas nacionales. Después de la entrada de España en la CEE (1986), más tarde con la entrada en vigor del Tratado de Maastricht (1993) y finalmente con la Unión Monetaria Europea en 1999, es evidente que se produjo un menoscabo en ese margen de maniobra de las políticas económicas españolas. Aunque los casos de desajustes y contagios internacionales al intentar coordinar la política monetaria ya habían provocado reacciones en cadena desde la Segunda Guerra Mundial. La pretensión de establecer una política monetaria autónoma siempre tuvo restricciones, como por ejemplo cuando el país deseaba mantener el comercio internacional y también una fluidez en los movimientos de capitales extranjeros. Este extremo se había comprobado fehacientemente en los años setenta, después de la desaparición del sistema monetario diseñado en Bretton Woods. Quedaba patente que no se podían mantener a la vez un tipo de cambio fijo, libertad de movimiento de capitales y política monetaria autónoma. Precisamente éste era el trilema de la política monetaria enunciado por Obstfeld y Taylor (2001), el cual se manifestaba porque una política macroeconómica debía incluir a lo sumo dos elementos de esa trinidad inconsistente ${ }^{60}$. Es preciso reconocer, como concluye Muñoz Cidad $(2008,60)$, que al final del siglo XX y en lo que va del siglo XXI se ha producido una reducción de la discrecionalidad de la política económica y que esto se debe en gran parte a restricciones del exterior. Las políticas económicas de los diferentes gobiernos de la nación fueron, a veces, producto del consenso entre los partidos políticos, en otras ocasiones aparecieron como lógica consecuencia del enfrentamiento y en algunos momentos surgieron a partir de la oposición responsable practicada por dichos partidos.

Después de haber repasado, en los epígrafes precedentes, los principales rasgos de las políticas económicas de los gobiernos conservadores y socialistas, se mantiene el interrogante sobre qué tipo de balance ofrece esa evolución histórica. ¿Se trata de una evaluación favorable a los gobiernos conservadores o bien al contrario arroja un resultado a favor de los no conservadores? Como ya dejé anunciado en la introducción de este artículo, las conclusiones de Mancha Navarro (2008) ofrecen una hipótesis de trabajo coherente con la información suministrada en su estudio. Su balance muestra la inexistencia de ciclos electorales o partidistas en el desempeño de la política económica de los diferentes partidos en el Gobierno, lo cual para él define que ésta ha sido la adecuada, hayan sido

60 A lo sumo pueden mantenerse dos de los tres objetivos políticos: Libertad de movimiento de capitales; tipo de cambio fijo; y política monetaria independiente orientada a objetivos internos. Ver Muñoz Cidad, Cándido (2008, 54-57). 
mejores o peores los resultados obtenidos ${ }^{61}$. Resulta trivial señalar que dicha hipótesis provoca por sí misma un gran interés por contrastarla.

Se puede convenir como una premisa relevante para cualquier análisis de la economía española de aquel período que, a pesar del aumento previo del paro, con anterioridad a una consulta electoral, el partido gobernante no resultaba afectado por un voto de castigo. Esto le sucedió al PSOE en dos ocasiones y eso que el desempleo rondaba la cifra del 20\%, situación que ahora, en 2010, sigue de actualidad ${ }^{62}$. En general, tanto populares como socialistas han tratado de lidiar con la inestabilidad de los precios, aunque desde el Tratado de Maastricht la reducción de la inflación era un objetivo declarado y asumido. Los mejores registros en la ratio de inflación fueron conseguidos por el Partido Popular y los peores por la UCD. Respecto a la variable crecimiento económico parece muy difícil afirmar la existencia de una manipulación preelectoral, tanto del PSOE como del PP, a pesar de la favorable evolución de esa variable en los trimestres tercero y cuarto de los respectivos mandatos ${ }^{63}$. La idea de un modelo español de ciclos político-económicos que contraste favorablemente (que confirme) el slogan de «Spain is different», respecto a los seguidos normalmente por las políticas económicas de las democracias occidentales, queda plasmada para el período 1977-2004 en el estudio de Mancha Navarro (2008) ${ }^{64}$. Me parece un hito la existencia de un estudio que pueda concluir, en este caso sobre los ciclos político-económicos, que España es diferente, porque me había acostumbrado a leer lo contrario ${ }^{65}$.

61 Mancha Navarro $(2008,109)$ indica que según la información manejada por él sólo se produce durante algunos trimestres de legislaturas concretas algún comportamiento electoral o partidista. Por lo cual en su análisis se concluye la inexistencia de una manipulación electoral o ideológica por parte de los gobiernos y la trayectoria económica guarda relación con la coyuntura económica.

62 Es el paradójico caso de las dos victorias del PSOE con mayoría absoluta, 1986 y 1989. Cit. en Mancha Navarro $(2008,107)$.

63 Según Mancha Navarro $(2008,106-7)$ los comportamientos electoralistas vendrían marcados por una expansión económica en los períodos preelectorales (tercer y cuarto año). También afirma este autor que con la información disponible para el período 1977-2004 no se produce una evolución de los datos congruente con los planteamientos teóricos. Ver cuadros 4, 5 y 6 con datos promedio y por trimestres, para las tres variables: crecimiento económico, inflación y desempleo. Ver Mancha Navarro (2008, 107-108).

64 Como es sabido el slogan pertenece a los tiempos en los que Manuel Fraga Iribarne era ministro de Información y Turismo. Al completo se leía: «Spain is different and beautiful». No estoy seguro que la segunda parte se pueda suscribir, al menos pensando en las elevadas tasas de desempleo soportadas por nuestra economía durante largos períodos.

65 Durante una temporada proliferaron los estudios que intentaban contrastar lo de Spain is different aplicado a cualquier aspecto histórico económico. Uno de esos estudios p.e. Molinas, Cesar y Prados de la Escosura, Leandro, «Was Spain different? Spanish histori- 
A la hora de valorar qué gobiernos administraron mejor lo público -el sector público-, cabe pensar que fueron aquellos que lograron un mayor bienestar económico para la nación, puesto que el bienestar humano tiene componentes subjetivos que lo hacen difícilmente medible. Pero no se debe perder de vista que si nos atenemos sólo a lo medido por los valores de las principales magnitudes macroeconómicas, estaremos obviando los dos objetivos más preciados conseguidos por los diferentes grupos políticos que gobernaron España, desde la Transición democrática hasta la actualidad ${ }^{66}$. A saber, por orden cronológico, en primer lugar el objetivo de consolidar la democracia y en segundo lugar, el de formar parte de la Unión Europea. Se canalizaron innumerables esfuerzos desde el Gobierno de la nación española, a través de la política económica en general, para salvaguardar esos dos objetivos centrales, incluso aunque no se declarasen como tales objetivos de ninguna política económica en particular, fuera ésta fiscal, monetaria, sectorial, regional o lo que fuera. Como afirma Fuentes Quintana $(1988,37)$, «una economía en crisis constituye un problema político fundamental».

En una primera aproximación se puede concluir, sin mucho temor a equivocarse, que el objetivo de consolidar y mantener una democracia, así como el de formar parte de la Unión Europea, fueron resultados indiscutibles sobre los cuales cabe poco debate en lo tocante a su logro, durante el período 1976-2006 ${ }^{67}$. Esta intuición sobre los dos objetivos con mayúsculas queda reforzada por las conclusiones del estudio de Mancha Navarro expuestas en el epígrafe anterior y además constituye una realidad que concitó durante una primera fase todos los esfuerzos políticos y los colocaba en posición subordinada: hubo consenso sobre

cal backwardness revisited», Explorations in Economic History, 26.4 (1989), pp. 385-402. También recuerdo la publicación del libro de Fusi y Palafox como un respaldo a la visión de España como un país normal, en contra de una excepcionalidad española entendida en clave negativa. Ver Fusi, Juan Pablo y PaLafox, Jordi, España: 1808-1996. El desafí de la Modernidad, Madrid, Editorial Espasa-Calpe, 1997. Aunque sorprenda la circunstancia de un crecimiento económico «milagroso» sin libertades constitucionales como el acaecido durante la etapa franquista, las analogías surgen con países incluso tan lejanos como Corea del Sur que durante más tiempo que España, soportó un régimen dictatorial y también un destacado crecimiento económico en la segunda mitad del siglo veinte.

66 Ya ha quedado claro con anterioridad que los márgenes de actuación para los partidos conservadores y socialistas que se alternaron en el poder habían sido reducidos debido a la mayor interdependencia de las economías.

67 Es decir que se debe notar en este párrafo cómo la palabra debates podría sustituir a los denominados instrumentos para alcanzar los objetivos de las políticas económicas o también a las denominadas variables intermedias. A posteriori es indudable la eficacia de los instrumentos elegidos a la hora de consolidar los dos principales objetivos, la democracia y la entrada en la Unión Europea, independientemente de los diferentes grados de eficiencia habidos en la implementación y resultados de las políticas económicas aplicadas. 
la necesidad de democracia ${ }^{68}$. El contrapunto estaba tan cercano y había durado casi cuarenta años que resulta innecesario abundar en cómo la percepción política de la alternativa a este objetivo tenía escasa posibilidad de prosperar. Los gobiernos tuvieron buen cuidado en su política económica para asegurar la consolidación de la democracia; mientras el miedo a una involución pudo ser el último criterio que guiaba unos comportamientos políticos, a la postre ni electoralistas ni partidistas.

Más arriesgado o bien más dudoso sería concluir con un ejercicio contrafactual sobre el bienestar económico logrado en el hipotético caso de haber quedado fuera de la Comunidad Europea, en lugar de haber pasado a ser parte de ella desde 1986 hasta la actualidad. Ninguno de los gobiernos, desde que a Solchaga le cupo el honor de asumir la integración de nuestro país en Europa, parece haber dudado de la trascendencia de este segundo gran objetivo político para España, sobre todo desde 1986 en adelante. Lo cual ha hecho que los instrumentos y las políticas económicas se supeditasen, primero, a la integración y después, a los objetivos de convergencia firmados, con la prioridad debida a nuestra inclusión en un ente supranacional y que, ciertamente, conllevaba y conlleva una pérdida de soberanía. Para muestra de esta soberanía mermada nos ha quedado la política monetaria como paradigma, pues la autoridad monetaria de España quedaba emplazada en Franckfurt (Banco Central Europeo) y dejaba de estar en Madrid (Banco de España). Dejando aparte la percepción general sobre esta cesión de soberanía política, para el período que nos ocupa desde la Transición democrática, y centrados en la segunda parte, desde 1986 a 2006, Torres Mancha no puede encontrar evidencia suficiente para calificar los comportamientos de los diferentes gobiernos -conservadores, o socialistas- ni de electoralistas, ni de partidistas.

\begin{tabular}{lcccc} 
Promedio de todo el mandato & UCD & PP & PSOE & $\begin{array}{c}\text { PROMEDIO } \\
1977-2007\end{array}$ \\
\hline Inflación & 16,54 & 2,63 & 6,34 & 7,96 \\
\hline Desempleo & 11,81 & 15,20 & 17,41 & 15,46 \\
\hline Crecimiento Económico & 0,68 & 3,68 & 2,76 & 2,30 \\
\hline
\end{tabular}

Fuente: Véase los cuadros desagregados por legislaturas para una información más precisa en Torres Mancha $(2008,95,97,106)$

La observación de políticas partidistas o electoralistas permitiría diferenciar

68 Sólo momentáneamente alterado por los sucesos del 23 de febrero de 1981, con los militares golpistas que tuvieron al teniente coronel Tejero de la Guardia Civil como líder del asalto al Parlamento de España. 
algunos mandatos del resto. Por consiguiente permitiría destacar los períodos que no muestran esos sesgos, como los mandatos de gobiernos que políticamente fueron más respetuosos con el bienestar económico de los ciudadanos. Pero el estudio de Torres Mancha apunta una evolución del ciclo político durante el período 1977-2007 que, con independencia de los resultados, refleja el desarrollo de unas estrategias democráticamente correctas. Con los resultados que aporta (ver cuadro anterior), los mejores registros son para el mandato del Partido Popular. Las paradojas han sido variopintas pues curiosamente la etapa socialista resultó menos inflacionista que la conservadora y asimismo UCD y PP registraron menores tasas de paro que las etapas socialistas. El crecimiento económico si se compara sólo la etapa PP con la del PSOE sigue siendo favorable a los conservadores, aunque la afirmación cambia de signo político en cuanto se computan los resultados de la UCD unidos a los del PP. Quedaría por medir el impacto de las hijuelas políticas y el peso de sus correspondientes cargas heredadas en cada cambio de Gobierno, de partidos conservadores a socialistas y viceversa ${ }^{69}$. En definitiva, la sensibilidad democrática de los gobernantes aparece como un instrumento más a la hora de administrar el sector público, pues muchos objetivos de política económica son difíciles de lograr sin las dosis adecuadas de ese ingrediente. Posiblemente la memoria colectiva de la larga etapa anterior facilita la pervivencia de esa sensibilidad también en los gobiernos de la nación cuando ponen orden en su agenda política.

El ciclo político económico en España durante el período de estudio no parece muy homologable con los de otras democracias (Torres Mancha, 2008), pero qué decir del supuesto modelo económico seguido en la época. Si hubo algún modelo fue el proporcionado por la experiencia democrática -así lo afirma Solchaga-, sobre el que crecía el bienestar económico del país ${ }^{70}$. Pero cuando

69 Cabría hablar de la gestión económica según las políticas arbitradas al efecto por el PP o por el PSOE, por ejemplo en materia tan relevante como la de sanidad. Actualmente se percibe un balance histórico muy negativo para el PP y bastante positivo para el PSOE respecto al tema sanitario por Comunidades Autónomas. Un ejemplo podría constituirlo la sanidad pública asturiana enfrentada al de su homóloga valenciana, pues en las tres últimas legislaturas el PSOE gobernaba en Asturias, mientras el PP lo hacía en Valencia. Los resultados parecen favorecer la gestión realizada en la sanidad asturiana durante los últimos doce años al menos, pero algunas evidencias no dejan demostrada la hipótesis de cuál fue la mejor gestión. En el terreno de las hipótesis sobre gestión de los presupuestos autonómicos y en correlación con las burbujas inmobiliarias o con los «pelotazos» del sector de la construcción (sector en el que se centra la crisis económica actual), cabría afirmar como más nefasta la gestión desarrollada por el PP que la del PSOE. Pero es preciso hacer el ejercicio que demuestre la veracidad de esa hipótesis.

70 Así lo afirma Carlos Solchaga, en un artículo periodístico. Ver SolchaGa, Carlos, «Política Económica y Democracia», Cinco días, 14-01-2008. 
llega la crisis de 2008 y se percibe ya la ralentización de la actividad económica en España, algunos reclamaban que era preciso abandonar el modelo vigente ${ }^{71}$. Se referían al modelo que había permitido un desarrollo desmedido del sector de la construcción y por ende resultaba desmedido igualmente el comportamiento bancario a la hora de asumir su prima de riesgo en la concesión, sobre todo, de los préstamos hipotecarios. Este tipo de problemas se siguen arrastrando, en 2010, tanto en la morosidad creciente por impago de esos préstamos, como en el lastre de las valoraciones que en el balance de los bancos supone la ejecución de esas hipotecas. Como ya afirmaba José A. Herce en 1996 y desgraciadamente se corrobora desde el 2006 en adelante para nuestra economía, «donde hay déficit no manda convergencia» ${ }^{72}$.

Aquel dicho político, tan en boga en los años de la Transición a la Democracia: ireforma o ruptura?, parece cobrar nueva vida cuando aún estaba en ciernes la crisis económica que quedó instalada desde 2008 en nuestra economía. Se empezaba planteando un dilema similar pero conceptual respecto al sistema capitalista, por los más conspicuos liberales o neoliberales. Sin ir tan lejos en la teoría y sin la necesidad ahora, en la España actual, de una ley fundamental de Reforma del Estado, la pregunta latente puede hacerse para las políticas económicas a debate: ¿reforma o ruptura? Sin embargo es poco realista en los tiempos que corren interrogarse sobre una salida del euro porque seguramente sería el final de la Unión Europea.

La contribución de Mancha Navarro deja demostrado lo que apunta como tesis sobre los procesos político-económicos que analiza: hubo ausencia de patrones electoralistas y partidistas durante el período 1977-2007. Si ningún grupo practicó políticas electoralistas ni partidistas se entiende que su aportación al bienestar económico de los ciudadanos es crucial, para determinar quién administró mejor el sector público. Una medida generalmente aceptada de la evolución de ese bienestar económico está contenida en el Producto Interior Bruto (PIB) per cápita (véase el siguiente gráfico).

71 Ver BOADA, Claudio, «Los retos de la economía española», ABC, 06-03-2008. En realidad como afirma Cuadrado Roura $(2000,22)$ la única exigencia de aquel modelo consistió en acoplarse a un sistema de Economía de Mercado durante la Transición democrática.

72 Cabe pensar que esto resulta tan válido para los keynesianos como también para los no keynesianos. Sobre la cita ver Herce, José A., «Política económica española: ¿qué hemos aprendido en diez años de integración europea?», en Circulo de Empresarios, Madrid, 1996, pp. 201-217, p. 213 
Variación interanual del Producto Interior Bruto de España, 1976-2000

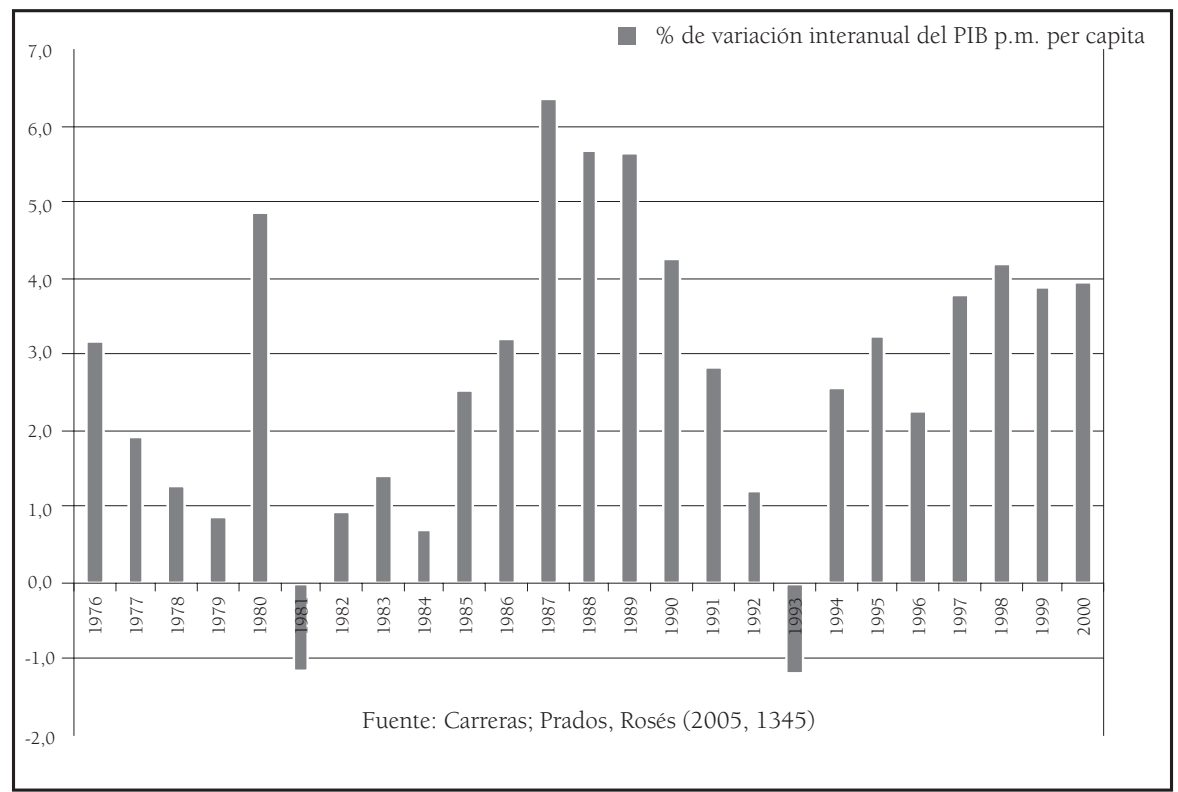

La evolución del PIB a precios de mercado (PIBpm) per cápita, según los datos disponibles, corrobora que la etapa de la Transición a la democracia en España (1974-1986) experimentaba una notable desaceleración del crecimiento ${ }^{73}$. A partir de 1986 se produjo una aceleración durante los seis años siguientes y le seguiría un ciclo depresivo de ese crecimiento económico (Carreras, Prados y Rosés, 2005, 1307). Después de las devaluaciones de la peseta decretadas por Solchaga y Solbes, desde 1996 hasta 2003, según los datos que ofrece Gámir (2008) el PP logra una ligera ventaja en su aportación al crecimiento respecto al PSOE de los años 2004-200774. Resulta imposible comparar los datos utilizados, pues la fuente última del gráfico anterior son las estimaciones realizadas por Leandro Prados $(2003)^{75}$, mientras que la fuente de los datos ofrecidos por

73 Esta visión tiene su lógica puesto que esa primera etapa de la democracia coincide justo después de los años del desarrollismo, y se suma la crisis del petróleo, la reconversión industrial y las políticas de ajuste a la crisis con la orientación para la entrada en la CEE.

74 Como apuntaba GÁmir $(2008,470)$ el PP con una tasa de crecimiento económico interanual -crecimiento real del PIB (\% de crecimiento sobre el año anterior)- del 3,7 \% se situaba para el período 1996-20003, ligeramente por encima del 3,6\% obtenido por el PSOE durante el lapso 2003-2007.

75 Más exactamente véase Prados (2003), cuadros A.11.7, pp. 601-605, y A.13.5, pp. 681- 
Gámir (2008) es Eurostat. Quedaría servido ya un posible debate, aunque primero habría que dilucidar otro metodológico para acordar qué cifras son las más verosímiles y obtener una serie de datos homogénea.

Por lo tanto las interpretaciones ofrecidas aquí, en el epígrafe España ya está dentro de Europa...ergo converge, sobre los resultados que ante la igualdad de comportamientos políticos -ni electoralistas, ni partidistas- favorece ligeramente al Partido Popular, pueden ser controvertidas. Tal vez cabe especular con las herencias recibidas de legislaturas anteriores a la hora de determinar lo relativo de los logros económicos alcanzados por cada grupo político. Pero lo que no parece demasiado refutable es esa aceleración del crecimiento económico per cápita (véase el gráfico) que se inicia en 1986 con el segundo mandato de Felipe González y dura hasta la crisis de 1992. El PSOE recibía su propia herencia, puesto que ya en la anterior legislatura había desempeñado el poder desde el Gobierno de la nación.

Una de las intuiciones que permitirían inclinar la opinión, bajo la restricción del balance global de Mancha Navarro (2008), hacia la percepción de una administración de lo público ligeramente mejor en el caso del Partido Popular, se encuentra en un estudio de Carreras y Tafunell (2008, 56 y 57) ${ }^{76}$. Estos autores afirman la existencia para Europa Occidental -España incluida- de una convergencia generalizada de las tasas de inflación para la década de 1990 y previamente señalan que la integración monetaria de esos años noventa había resultado, en perspectiva de largo plazo, extraordinaria. Aunque aceptásemos esta última consideración quedaría por aclarar si los años de la estanflación desde 1974 en adelante, serían un criterio correcto para comparar la administración del sector público, y utilizar la época posterior a la entrada en la CEE, desde $1986^{77}$, como línea divisoria, para desde ahí hasta el 2007 valorar qué grupo político mejoraba más el bienestar económico de los españoles. Se pueden dar muchos supuestos y sobre todo hay que especificar los criterios, pero lo que sí parece evidente es que estas valoraciones conseguirán debates bastante animados.

685.

76 Cuando Carreras y Tafunell (2008, 3 y 63) tratan de Europa Occidental se refieren a la Unión Europea de los 15 más Noruega y Suiza, la Europa del Tratado de Maastricht. Aunque advierten que no tienen datos de Luxemburgo.

77 La división por fases del progreso de España que hace Prados $(2003,230)$ distingue la de 1974-2000 como algo homogéneo, dentro de la que se da una fase de menor pujanza, la de 1974-1986. 


\section{BibLIOGRAFÍA}

Argandoña, Antonio et al. (1996), Círculo de Empresarios, Política económica española: ¿qué hemos aprendido tras diez años de integración?, Madrid, Artes Gráficas Cuesta.

Argandoña, Antonio et al. (2003), Círculo de Empresarios, España-Europa: Distintas alternativas para el crecimiento, Madrid, Artes Gráficas Muriel.

Bernaldo DE Quirós, Lorenzo (2004), «Del estatismo a la libertad. La política económica española durante la democracia», en 25 años de economía de mercado. I. El progreso de la economía española, Revista del Instituto de Estudios económicos, 1, pp. 111-146.

BoAda, Claudio (2008), «Los retos de la economía española», ABC, 06-03-2008.

Carreras, Albert y Tafunell, Xavier (2004), Historia Económica de la España Contemporánea, Barcelona, Crítica.

Carreras, Albert y Tafunell (2008), Xavier, Crecimiento a largo plazo en Europa occidental, 1830-2000: hechos y problemas, Barcelona, Centre de Recerca en Economia Internacional.

Carreras, Albert, Prados de la Escosura, Leandro y Rosés, Juan (2005), «Renta y riqueza», en Estadísticas Históricas de España. Siglos XIX-XX, Fundación BBVA, Bilbao, segunda edición, revisada y ampliada, pp. 1299-1376.

CASEs, Pedro (1985), «La privatización de Entursa y Marsans divide al gobierno en dos bloques», El País, Madrid, 11/06/1985.

Clifton, Judith, Comín, Francisco y Díaz Fuentes, Daniel (2003), Privatisation in the European Union. Public Enterprise and Integration, Dordrecht, Kluwer Academic Publishers.

Cuadrado Roura, Juan R., dir. (2001), Política económica. Objetivos e instrumentos, Madrid, McGraw-Hill.

Cuadrado Roura, Juan R. (2008), «La productividad: evolución y políticas», Política económica de España, Madrid, Alianza Editorial, 8. a ed., pp. 63-90.

Dehesa, Guillermo de la (2007), Comprender la globalización, Madrid, Alianza Editorial.

Fuentes Quintana, Enrique (1988), «Tres decenios de la economía española en perspectiva», en García Delgado, José Luis, dir., España. Economía, Madrid, Espasa-Calpe, pp. 1-75.

Fusi, Juan Pablo y Palafox, Jordi (1997), España: 1808-1996. El desafío de la Modernidad, Madrid, Editorial Espasa-Calpe. 
Foreman-PeCk, James S. (1998), «European industrial policy and desindustrialization: a historical perspective», en De-industrialisation in Europe, $19^{\text {th }}-20^{\text {th }}$ centuries, Sevilla, Secretariado de Publicaciones de la Universidad de Sevilla.

Gámir, Luis, dir., Casares, Javier y Velasco, Carlos, coords. (2008), Política económica de España, Madrid, Alianza Editorial, 8. ${ }^{\mathrm{a}} \mathrm{ed}$.

GÁmir, Luis (2008), «La política económica desde el período autárquico», en Política económica de España, Madrid, Alianza Editorial, 8. ${ }^{\text {a }}$ ed., pp. 23-62.

GÁmir, Luis (2008), «Los objetivos económicos», en Política económica de España, Madrid, Alianza Editorial, 8. ${ }^{\text {a }}$ ed., pp. 23-62.

GÁmir, Luis y DurÁ, Pedro (2004), «Veintisiete años de política económica: una interpretación», en 25 años de economía de mercado I El progreso de la economía española, Revista del Instituto de Estudios económicos, 1, pp. 97-110.

Herce, José A. (1996), «Política económica española: ¿qué hemos aprendido en diez años de integración europea?», en Circulo de Empresarios, Madrid.

Leboutte, René (1997), Vie et mort des bassins industriels en Europe, 1750-2000, Paris, L'Harmattan.

Mancha Navarro, Tomás (2008), «El ciclo político-económico en la democracia», en Política económica de España, Madrid, Alianza Editorial, 8. ${ }^{a}$ ed., pp. 91110 .

Marco, Luis (1993), «Política económica y las reformas estructurales de la economía española», en Política económica y las reformas estructurales de la economía española, Círculo de empresarios, Madrid, pp. 245-267.

Martínez Álvarez, José Antonio y Calvo, José Luis, eds. (2008), Política económica en la España democrática, Valencia, Tirant lo Blanch.

Martínez Arévalo, Luis (1993), «La política de privatizaciones: algunas consideraciones poco usuales», en Política económica y las reformas estructurales de la economía española, Madrid, Círculo de empresarios, pp. 269-281.

MокYR, Joel (1990), The lever of riches. Technological creativity and economic progress, New York, Oxford University Press.

Muñoz Cidad, Cándido (2008), «El escenario internacional de la política económica», en Política económica de España, Madrid, Alianza Editorial, 8. ${ }^{a}$ ed., pp. 47-62.

Myro, Rafael (1997), "Crecimiento económico y cambio estructural desde 1960», en Lecciones de economía española, Madrid, Editorial Civitas, 3. ${ }^{a}$ ed., pp. 49-72. 
North, Douglas C. (1984), Estructura y cambio en la historia económica, Madrid, Alianza Editorial.

Prados de la Escosura, Leandro (2003), El progreso económico de España (18502000), Bilbao, Fundación BBVA.

Segura, Julio (1998), «Intervención pública y política del bienestar: el papel del Estado», en España. Economía, Madrid, Espasa-Calpe, pp. 831-857.

Solchaga, Carlos (2008), «Política Económica y Democracia», Cinco días, $14 / 01 / 2008$

Tizón, Álvaro (2007), «Fuentes Quintana, el economista que gestó los Pactos de la Moncloa», E1Mundo, 11/06/2007.

Torrero, Antonio (1997), «Retos y problemas de una economía abierta», en Lecciones de economía española, Madrid, Editorial Civitas, 3. ${ }^{\text {a }}$ ed., pp. 541-555.

Trías Fargas, Ramón (1973), Principios de Economía Política Española, Barcelona, Ediciones Ariel.

Tusell, Javier y Soto, Álvaro, eds. (1996), Historia de la transición (1975-1986), Madrid, Alianza Universidad.

TRulLÉn, Joan (1993), «La política de rentas en el proceso de ajuste y reforma de la economía española», en Política económica y las reformas estructurales de la economía española, Madrid, Círculo de empresarios, pp. 439-457.

Velarde, Juan (1993), «El miedo ante el cambio de las estructuras socioeconómicas españolas», en Política económica y las reformas estructurales de la economía española, Madrid, Círculo de empresarios, pp. 459-499. 